\title{
Rolling paths design assisted by target-temperature driven intelligent FE simulation of radial-axial ring rolling
}

\author{
Xuechao $\mathrm{Li}^{1,2}$, Lianggang Guo ${ }^{1,2,}$, Yifan $\mathrm{Wang}^{2}$, and Lei Liang ${ }^{1,2}$ \\ ${ }^{1}$ Research \& Development Institute of Northwestern Polytechnical University in Shenzhen, Shenzhen 518057, PR China \\ ${ }^{2}$ School of Materials Science and Engineering, Northwestern Polytechnical University, Xi'an 710072, PR China
}

Received: 16 April 2019 / Accepted: 24 June 2019

\begin{abstract}
The microstructures of hard-to-deform materials such as titanium alloy are very sensitive to temperature change in hot working process. During ring rolling process, unreasonable rolling paths will lead to drastic temperature change in local region of ring, thus damaging the microstructure and performance of rolled ring. This work proposes a method for designing the rolling paths which could accurately control the ring temperature by target-temperature driven intelligent FE simulation. The main idea of target-temperature driven intelligent simulation is introduced. An intelligent 3D-FE model for TA15 titanium alloy ring rolling is established under ABAQUS/Explicit environment. The rolling paths under different initial conditions are obtained by intelligent FE simulations. The influence rule of initial conditions on rolling paths is revealed. The temperature control effects and change under different initial conditions are discussed. Considering the temperature control effects, a feasible range of initial ring temperature is suggested. Using the proposed method, the quick and accurate design for the rolling paths in radial-axial ring rolling process is realized. It is of great significance for the design and optimization of rolling paths and the accurate regulation of ring temperature in actual production.
\end{abstract}

Keywords: Radial-axial ring rolling / rolling paths / target-temperature driven intelligent simulation / temperature control / TA15 titanium alloy

\section{Introduction}

With the rapid development of aerospace industry, the demand for aerospace equipment with light weight but high performance has becoming increasingly urgent [1]. TA15 titanium alloy rings, as the core component of aero engine casting, have been extensively employed in aircraft engine-building, rocket and space engineering, due to its unique performances of high specific strength, excellent thermal stability, welding performance and strong corrosion resistance [2-4]. The radial-axial ring rolling has become an irreplaceable advanced manufacturing technology for hard wrought alloy like TA15 titanium alloy, because of its some advantages such as high quality, high efficiency and considerable saving in energy and material cost [5-7].

TA15 titanium alloy is very sensitive to deformation temperature, leading to complicated microstructure evolution with the thermal-mechanical coupling effects [8].

\footnotetext{
* e-mail: glgglg66@nwpu.edu.cn
}

The radial-axial ring rolling is a complicated dynamic forming process with multi-factor coupling effects of geometrical, physical and boundary nonlinearity. During ring rolling process, the ring temperature depends on the coupling effects of many factors, such as initial forming temperature, deformation heat, friction heat and heat loss $[9,10]$. It is difficult to accurately control the ring temperature during the whole process. The rolling paths define the motions of various rolls in ring rolling process, which have crucial influences on the ring temperature, thus greatly affecting the microstructure and performance of titanium alloy components [11-13]. Therefore, it is crucial to obtain the reasonable rolling paths by which the ring temperature can be controlled within a desired range during ring rolling process, thus improving the microstructure and performance of rolled ring.

As we all know, the finite element simulation technology has become a powerful means to study the plastic forming process [14-16], by which many research has been performed for ring rolling process. Using dynamic explicit FE simulation, the reasonable ranges of the rotational speed of main roll and feed rate of mandrel 
were determined [17], respectively. This lays a foundation for the study on hot radial-axial rolling of large titanium alloy rings. Anjami et al. reported that changing the sizes of forming rolls could considerably affect the strain and temperature distribution, thus affecting the forming quality of the rolled ring [18], which could serve as a guide for the design of rolls sizes and optimization of the hot ring rolling of TC4 titanium alloy. In hot rolling of large rings of titanium alloy, the ratio of roll radii has a significant effect on the geometric shape of deformation zone [19]. Moreover, there exists an optimized range of the ratio of roll radii, which plays a decisive role in achieving large titanium alloy rings with high quality. However, in these studies, the motions of all rolls which decide the rolling paths are mainly defined by production experience. This does not accord with the actual production. Moreover, the ring temperature could not be controlled accurately. In addition, the trial and error method is always employed in current numerical modeling and simulation. This not only leads to lower efficiency, but also could not accurately control the temperature of ring during rolling process.

To overcome the shortcomings of traditional FE simulations, an intelligent simulation method driven by the control objective has been proposed [20]. In this method, the motions of various rolls could be driven automatically during the FE analysis by the control objective. It has been successfully employed to control the rolling force during radial-axial ring rolling of supersized aluminum alloy ring $[21,22]$. Similarly, taking ring temperature as the control objective, the intelligent control of ring temperature could be realized in radial-axial ring rolling process. The essence of accurate temperature control is to acquire the rolling paths which satisfy the temperature control objective.

To realize accurate control for ring temperature, this work proposes a method to design the rolling paths by the target-temperature driven intelligent FE simulation. The main idea for target-temperature driven intelligent $\mathrm{FE}$ simulation is introduced. Through VUAMP subroutine development under ABAQUS/Explicit environment, the intelligent temperature control method is integrated into the FE solver. An intelligent 3D-FE model for radial-axial ring rolling of TA15 titanium alloy is established. By intelligent FE simulations, the rolling paths under different initial conditions, namely the initial ring temperatures and initial ring growth velocities, are obtained. The temperature control effects under designed rolling paths are discussed. The influence rules of initial conditions on rolling paths and temperature control effects are revealed. This work provides an innovative method for the design and optimization of rolling paths and the accurate regulation of ring temperature in radial-axial ring rolling process.

\section{Target-temperature driven intelligent FE simulation of radial-axial ring rolling}

\subsection{Idea of target-temperature driven intelligent FE simulation}

During ring rolling process, the ring temperature depends on the comprehensive effects of initial ring temperature, deformation heat, friction heat and heat loss by interaction, convection and emissivity. According to the energy conversion in physics, the deformation heat mainly derives from the work done by external forces. When other forming conditions remain unchanged, the faster the deformation velocity of material, the greater the rolling force. The amount of work done per unit time increases, thus the deformation heat per unit time increases. Meanwhile, the rolling time will be reduced due to fast deformation, thus the heat loss decreases. This eventually leads to the rise of ring temperature. The slower the deformation velocity of material, the smaller the rolling force. The amount of work done per unit time decreases, thus the deformation heat per unit time decreases. The rolling time becomes long due to the slow deformation, thus the heat loss increases. This eventually leads to the drop of ring temperature.

The ring blank is deformed under the coordinate motions of all the rolls in ring rolling process. Therefore, the ring temperature can be controlled by adjusting the motions of all the rolls (rolling paths) to regulate the heat generation and heat loss. Based on this, the targettemperature driven intelligent FE simulation of radialaxial ring rolling is proposed in this work. Without predefining rolling paths, the intelligent simulation can realize the adaptive control of the rolls by detecting ring temperature. Driven by the temperature control objective, the rolling paths can be adjusted real-timely to maintain the ring temperature within the desired range. The main idea of target-temperature driven intelligent FE simulation of radial-axial ring rolling is shown in Figure 1.

From Figure 1, a desired range of ring temperature ( $T_{\text {obj-min }} \sim T_{\text {obj-max }}$ ) is determined to be the temperature control objective according to the microstructure and properties of the studied material before FE calculation. As the initial conditions of intelligent simulation for ring rolling, the initial ring temperature $T_{0}$ and initial ring growth velocity $v_{D 0}$ are preset. The preset initial ring temperature $T_{0}$ is determined according to the material behaviors, and the preset initial ring growth velocity $v_{D 0}$ is predesigned to ensure a successful establishment of ring rolling process. The main roll is used to drive the motion of ring, whose rotational speed is $n_{1}$. The rolling curve, which describes the relation between the instantaneous height $h$ and the instantaneous thickness $b$ of ring during ring rolling process, is predefined as $h=I(b)$, as shown in Figure 2. The instantaneous outer diameter $D_{t}$ and thickness $b$ could be monitored real-timely in each increment by the virtual sensors. Then the instantaneous height of ring $h$ can be calculated by the relation of $h=I(b)$.

The feed rate of mandrel $v_{f}$, feed rate of upper axial roll $v_{a}$ and withdrawal speed of axial rolls $v_{w}$ can be determined by equation (1):

$$
\left\{\begin{aligned}
v_{f} & =\frac{v_{D}}{\left[\frac{\left(D_{0}+d_{0}\right) h_{0} b_{0}}{2 h b^{2}}+\frac{\left(D_{0}+d_{0}\right) h_{0} b_{0} I^{\prime}(b)}{2 h^{2} b}-1\right]} \\
v_{a} & =v_{f} I^{\prime}(b) \\
v_{w} & =\frac{v_{D}}{2}
\end{aligned}\right.
$$




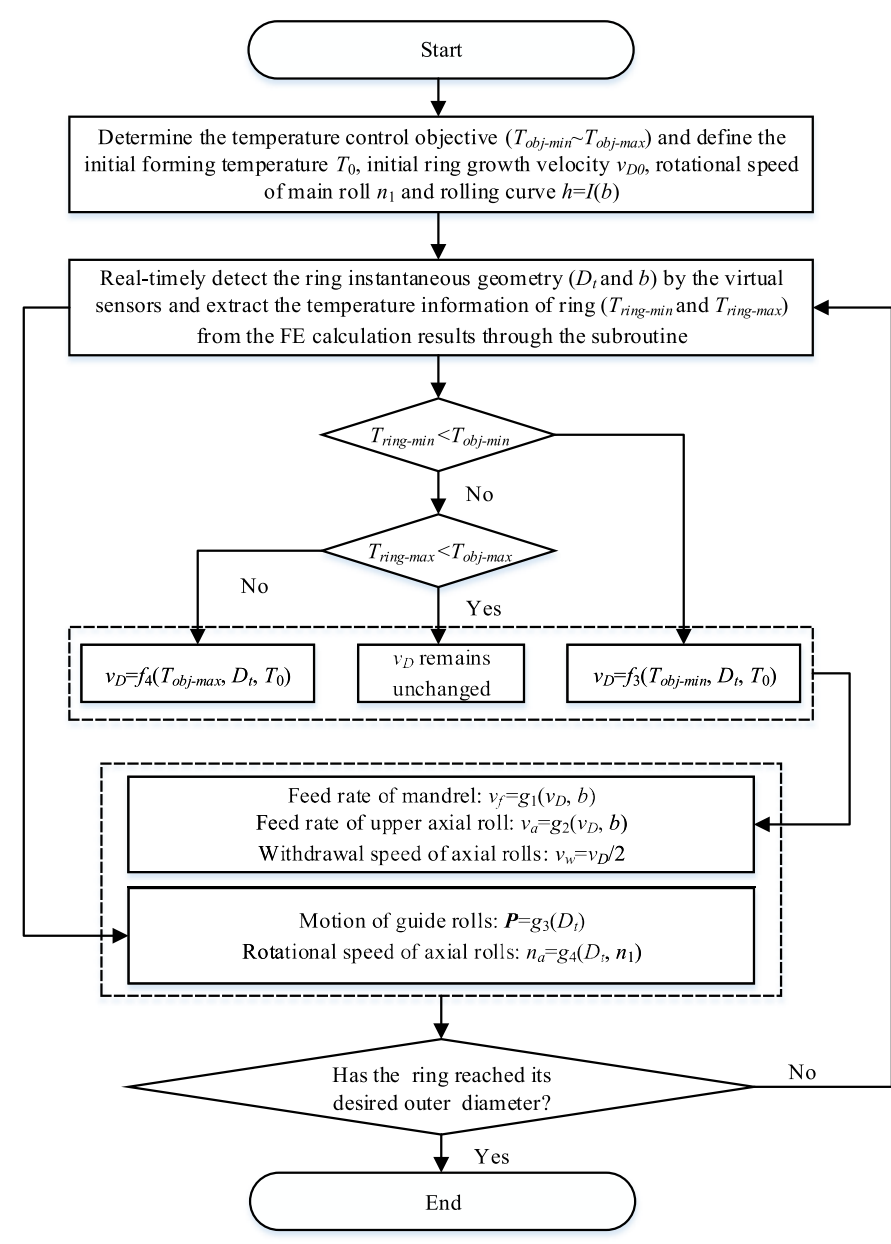

Fig. 1. Main idea of target-temperature driven intelligent FE simulation of radial-axial ring rolling.

where $v_{D}$ is the growth velocity of ring diameter; $D_{0}, d_{0}, b_{0}$ and $h_{0}$ are the outer diameter, inner diameter, thickness and height of ring blank, respectively; $b$ and $h$ are the instantaneous thickness and height of ring, respectively; $I^{\prime}(b)$ is the slope of rolling curve $h=f(b)$, which describes the instantaneous assignment of deformation amount between axial and radial directions.

The rotational speed of axial rolls and the instantaneous position of guide rolls could be determined by equation (2):

$$
\left\{\begin{array}{l}
n_{a}=\frac{2 n_{1} R_{1}}{D_{t} \sin \theta} \\
P=g_{3}\left(D_{t}\right)
\end{array}\right.
$$

where $n_{1}$ and $R_{1}$ is the rotational speed and radius of the main roll, respectively; $D_{t}$ is the instantaneous outer diameter of ring during ring rolling process; $\theta$ is the half cone angle of the axial rolls; $\boldsymbol{P}=g_{3}\left(D_{t}\right)$ denotes the relation between the instantaneous positions of guide rolls $\boldsymbol{P}$ and the instantaneous outer diameter of ring $D_{t} . \boldsymbol{P}$ stands for the instantaneous position vector of guide rolls in ring rolling process.

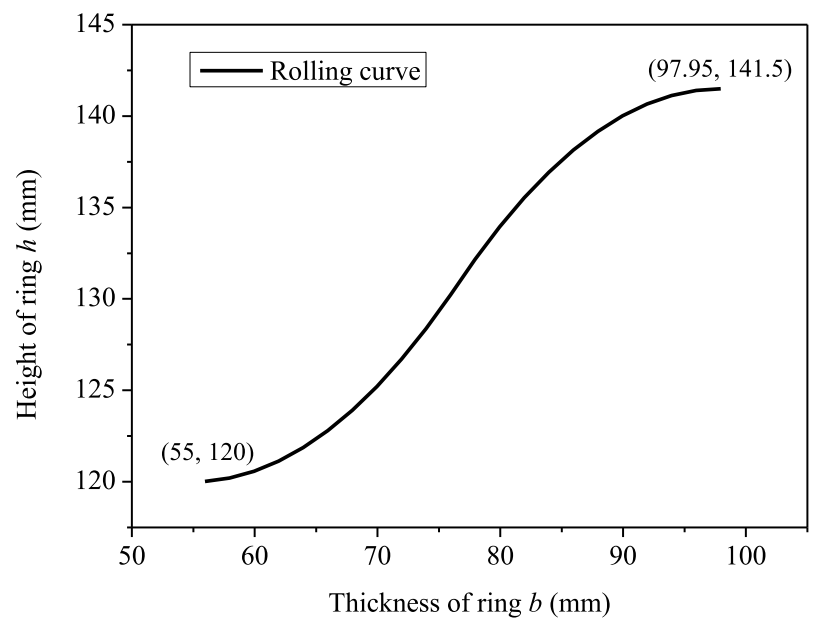

Fig. 2. Rolling curve for intelligent FE simulation of radial-axial ring rolling.

From equations (1) and (2), it can be seen the motions of all the rolls could be driven by the ring growth velocity $v_{D}$ and the instantaneous outer diameter of ring $D_{t}$ during ring rolling process [7]. Therefore, the adaptive regulation of ring temperature could be realized by developing a ring growth velocity model relating to the ring temperature.

To develop the ring growth velocity model relating to the ring temperature, the mathematical relations between ring temperature $\left(T_{\text {ring-min }}\right.$ and $\left.T_{\text {ring-max }}\right)$ and ring growth velocity $v_{D}$, initial temperature of ring $T_{0}$ and the instantaneous outer diameter of ring $D_{t}$ are established firstly, which is described as follows.

Through intelligent simulations under different $v_{D}, T_{0}$ and $D_{t}$, the information of ring temperature is extracted from the FE calculation results through the VUAMP subroutine. By sorting the temperatures of all elements in each increment, the instantaneous minimum temperature and maximum temperature of ring $\left(T_{\text {ring-min }}\right.$ and $\left.T_{\text {ring-max }}\right)$ are obtained, respectively. Then by polynomial regression analysis, the established mathematical model can be expressed as

$$
\left\{\begin{array}{l}
T_{\text {ring-min }}=f_{1}\left(v_{D}, D_{t}, T_{0}\right) \\
T_{\text {ring-max }}=f_{2}\left(v_{D}, D_{t}, T_{0}\right)
\end{array} .\right.
$$

By substituting temperature control objective ( $T_{\text {obj-min }}$ and $\left.T_{\text {obj-max }}\right)$ for $T_{\text {ring-min }}$ and $T_{\text {ring-max }}$ in equation (3), the equations about $v_{D}$ can be obtained. Then solving the obtained equations, the ring growth velocity model relating to the temperature control objective $\left(T_{\text {obj-min }}\right.$ and $\left.T_{\text {obj-max }}\right)$, instantaneous outer diameter of ring $D_{t}$ and initial temperature of ring $T_{0}$ can be expressed as

$$
\left\{\begin{array}{l}
v_{D}=f_{3}\left(T_{\text {obj-min }}, D_{t}, T_{0}\right) \\
v_{D}=f_{4}\left(T_{\text {obj-max }}, D_{t}, T_{0}\right)
\end{array}\right.
$$


Considering the equations about $v_{D}$ above may have no solutions, the established ring growth velocity model has five cases:

\section{See equation (5) below}

where $v_{D \min }$ and $v_{D \max }$ are the minimum and maximum values of ring growth velocity determined by the penetrating and gripping conditions during ring rolling process [14].

Based on this model, by comparing the obtained ring temperature (maximum and minimum temperature) with the temperature control objective, the ring growth velocity can be adjusted real-timely to maintain the ring temperature within the desired range, as shown in Figure 1. If both the maximum temperature and minimum temperature are within the desired temperature range ( $T_{\text {ring-min }}>T_{\text {obj-min }}$ and $T_{\text {ring-max }}<T_{\text {obj-max }}$ ), it is thought that current ring temperature meets the temperature control objective. Therefore, the ring growth velocity $v_{D}$ remains the current value unchanged. Inversely, if the maximum temperature or minimum temperature is beyond the temperature control objective, the developed ring growth velocity model will be adopted to adjust the current rolling paths to control ring temperature back to the desired range. At this time, for $T_{\text {ring-min }}<T_{\text {obj-min }}$, if $f_{3}\left(T_{\text {obj-min }}, D_{t}, T_{0}\right) \geq v_{D \max }$ or in the case of no solution, the maximum ring growth velocity $v_{D \max }$ allowed by the gripping conditions will be employed to increase the generation of deformation heat; for $T_{\text {ring-max }}>T_{\text {obj-max }}$, if $f_{4}\left(T_{\text {obj-max }}, D_{t}, T_{0}\right) \leq v_{D \min }$ or in the case of no solution, the minimum ring growth velocity $v_{D \text { min }}$ allowed by the penetrating conditions will be employed to decrease the generation of deformation heat.

From the developed $v_{D}$ model, the temperature control objective $\left(T_{\text {obj-min }}\right.$ and $\left.T_{\text {obj-max }}\right)$, instantaneous outer diameter of ring $D_{t}$ and initial temperature of ring $T_{0}$ are the parameters affecting the ring growth velocity. The former is predefined according to the intrinsic properties of material. The instantaneous outer diameter $D_{t}$ could be monitored in real time by virtual sensors. The initial ring temperature $T_{0}$ is predefined, which is a key factor significantly affecting the ring temperature. Additionally, as an initial designed variable to ensure the success of rolling process, the different values $\left(v_{D 01}, v_{D 02}\right)$ of $v_{D 0}$ will lead to obvious change of subsequent ring growth velocity, as shown in Figure 3. This eventually affects the rolling paths and the ring temperature. Therefore, the influence rules of the two factors $\left(T_{0}\right.$ and $\left.v_{D 0}\right)$ on the rolling paths and temperature control effects will be discussed in this work.

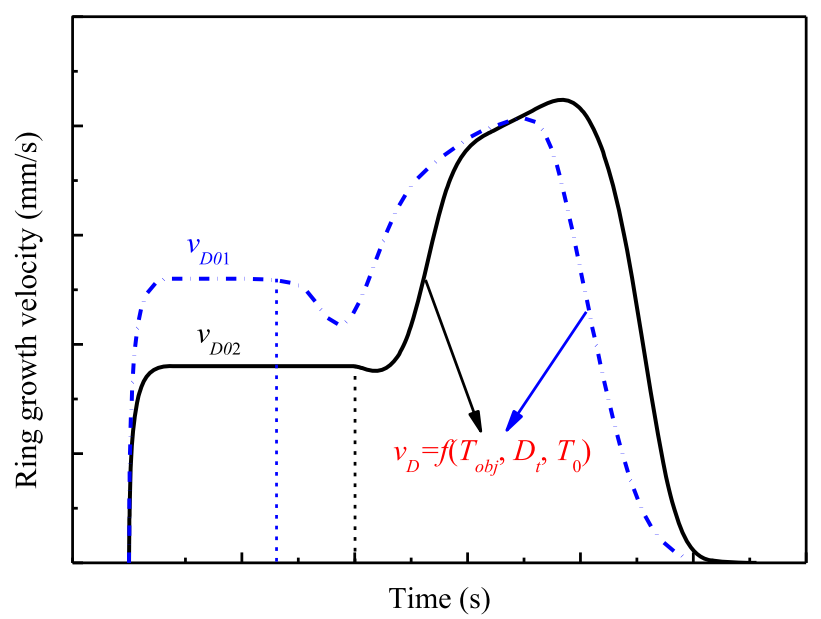

Fig. 3. Change of growth velocity of ring diameter with the rolling time.

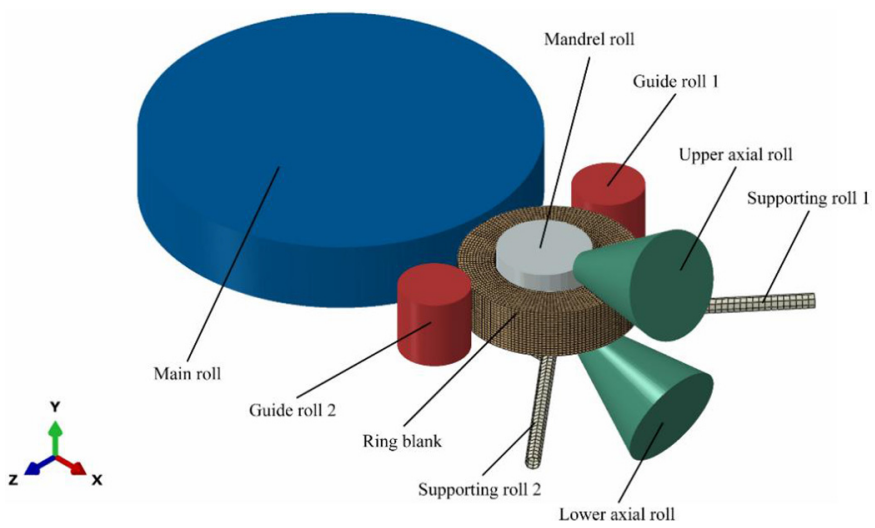

Fig. 4. 3D-FE model for radial-axial ring rolling.

\subsection{Target-temperature driven intelligent FE model of radial-axial ring rolling}

To validate the feasibility of the intelligent temperature control idea proposed above, FE simulation experiments for radial-axial ring rolling process are performed. The established 3D coupled thermo-mechanical FE model in this work is shown in Figure 4.

The blank material used in FE model is TA15 titanium alloy, whose density and Poisson ratio are $4450 \mathrm{~kg} / \mathrm{m}^{3}$ and 0.39 , respectively. The temperature-dependent physical
$v_{D}=\left\{\begin{array}{l}v_{D \max } \\ f_{3}\left(T_{\text {obj-min }}, D_{t}, T_{0}\right) \\ \text { remains current value } \\ f_{4}\left(T_{\text {obj-max }}, D_{t}, T_{0}\right) \\ v_{D \min }\end{array}\right.$

for $\quad T_{\text {ring-min }}<T_{\text {obj-min }}, f_{3}\left(T_{\text {obj-min }}, D_{t}, T_{0}\right) \geq v_{D \max }$ or no solution

for $\quad T_{\text {ring-min }}<T_{\text {obj-min }}$ and $f_{3}\left(T_{\text {obj-min }}, D_{t}, T_{0}\right)<v_{D \max }$

for $\quad T_{\text {ring-min }}>T_{\text {obj-min }}$ and $T_{\text {ring-max }}<T_{\text {obj-max }}$

for $\quad T_{\text {ring-max }}>T_{\text {obj-max }}$ and $f_{4}\left(T_{\text {obj-max }}, D_{t}, T_{0}\right)>v_{D \text { min }}$

for $\quad T_{\text {ring-max }}>T_{\text {obj-max }}, f_{4}\left(T_{\text {obj-max }}, D_{t}, T_{0}\right) \leq v_{D \text { min }}$ or no solution 
Table 1. FE simulation parameters.

\begin{tabular}{ll}
\hline Parameters & Value \\
\hline Ring outer diameter, inner diameter and height $(\mathrm{mm})$ & $900.0,790.0,120.0$ \\
Blank outer diameter, inner diameter and height $(\mathrm{mm})$ & $500.3,304.4,141.5$ \\
Radii of main roll, mandrel and guide rolls $(\mathrm{mm})$ & $550.0,130.0,100.0$ \\
Conical angle of axial rolls $\left(^{\circ}\right)$ & 35 \\
Temperature of rolls $\left({ }^{\circ} \mathrm{C}\right)$ & 300 \\
Temperature of ambient $\left({ }^{\circ} \mathrm{C}\right)$ & 25 \\
Rotational speed of main roll $(\mathrm{rad} / \mathrm{s})$ & 2.1 \\
Friction coefficient & 0.3 \\
Convective heat transfer coefficient $\left(\mathrm{W} /\left(\mathrm{K} \mathrm{m}^{2}\right)\right)$ & 17.2 \\
Thermal emissivity $\left(\mathrm{W} /\left(\mathrm{m}^{2} \mathrm{~K}^{4}\right)\right)$ & 0.7 \\
Interfacial heat transfer coefficient $\left(\mathrm{W} /\left(\mathrm{K} \mathrm{m}^{2}\right)\right)$ & 4000 \\
\hline
\end{tabular}

properties of TA15 titanium alloy, including Yong's modulus, specific heat, thermal conductivity and linear expansion coefficient, are derived from the reference [23]. The constitutive relationship reported by Shen [24] is employed to describe the plastic deformation behavior of TA15 titanium alloy.

In the model, the coupled thermo-mechanical elasticplastic dynamic explicit approach and mass scaling are adopted to accelerate the computation. The ring is meshed by the coupled thermo-mechanical hexahedron element with eight nodes (C3D8RT). An adaptive meshing technology is employed for the whole ring blank to maintain a highquality mesh throughout the analysis. The reduction integration and hourglass control are utilized to shorten the computation time and avoid the zero-energy model induced by the bending model of deformation.

The ring blank and all the rolls are treated as deformable body and rigid bodies, respectively. Eight contact pairs exist between the ring and the rolls. The friction conditions and contact heat conduction at the interface of every contact pair are defined. The modified Coulomb friction model is adopted and the friction coefficients are assumed to be constant during the whole analysis. The guide rolls and supporting rolls are assumed to be smooth surfaces, thus the friction coefficients on them are zero. The needed simulation parameters are listed in Table 1.

Through VUAMP subroutine development under ABAQUS/Explicit environment, the intelligent temperature control method above is implemented into the $3 \mathrm{D}-\mathrm{FE}$ model of radial-axial ring rolling for TA15 titanium alloy. The ring growth velocity can be adjusted in real time by tracing the temperature control objective, thus maintaining ring temperature within the desired range during the whole process. As the initial conditions of intelligent simulation, different $T_{0}$ and $v_{D 0}$ will affect the rolling paths, thus resulting in difference in temperature control effects of ring.

\section{Results and discussion}

To obtain the rolling paths under different initial conditions and study the influence rules of different initial conditions on the rolling paths and temperature control effects, the intelligent FE simulations are performed under different $T_{0}$ and $v_{D 0}$. Based on the intelligent temperature control idea shown in Figure 1, the temperature control objective ( $T_{\text {obj-min }} \sim T_{\text {obj-max }}$ ), initial temperature of ring $T_{0}$ and initial ring growth velocity $v_{D 0}$ need to be predefined before FE calculations. The phase transformation temperature of TA15 titanium alloy is $985^{\circ} \mathrm{C}[25]$, and its forgingending temperature should be larger than $850^{\circ} \mathrm{C}[26]$. To keep better comprehensive mechanical performance and low deformation resistance, the lower limit and upper limit of temperature control objective are set to be $900{ }^{\circ} \mathrm{C}$ and $980^{\circ} \mathrm{C}$, respectively. Considering the temperature drop during the transfer and rolling process, the range of initial ring temperature $T_{0}$ is set to be $900-970{ }^{\circ} \mathrm{C}$. Based on the gripping and penetrating conditions of steady rolling [14], the range of initial ring growth velocity $v_{D o}$ is determined to be $6-35 \mathrm{~mm} / \mathrm{s}$. Here, initial ring temperature $T_{0}$ is set as $915^{\circ} \mathrm{C}, 920^{\circ} \mathrm{C}, 925^{\circ} \mathrm{C}, 930^{\circ} \mathrm{C}, 935^{\circ} \mathrm{C}, 940{ }^{\circ} \mathrm{C}, 945^{\circ} \mathrm{C}$ and $950^{\circ} \mathrm{C}$, respectively. Initial ring growth velocity $v_{D 0}$ is set as $6 \mathrm{~mm} / \mathrm{s}, 20 \mathrm{~mm} / \mathrm{s}$ and $35 \mathrm{~mm} / \mathrm{s}$, respectively.

\subsection{Rolling paths by target-temperature driven intelligent simulation}

\subsubsection{Rolling paths under different initial conditions}

During the target-temperature driven intelligent simulation, the ring growth velocity $v_{D}$ with respect to the rolling time can be output by the VUAMP subroutine development. The feed rate of mandrel $v_{f}$ and feed rate of upper axial roll $v_{a}$ with respect to the rolling time can be extracted from the output database after FE calculation. Then the variation curves of ring growth velocity, feed rates of mandrel and upper axial roll with respect to the rolling time, namely the rolling paths, can be obtained.

Considering the rolling time is different while the outer diameter of rolled ring is the same under different initial conditions, the variation curves of ring growth velocity, feed rates of mandrel and upper axial roll with respect to the outer diameter of ring $D_{t}$ are also given. Here, the outer diameter of ring $D_{t}$ can be detected by virtual sensors and output by the VUAMP subroutine during intelligent simulation of ring rolling. 

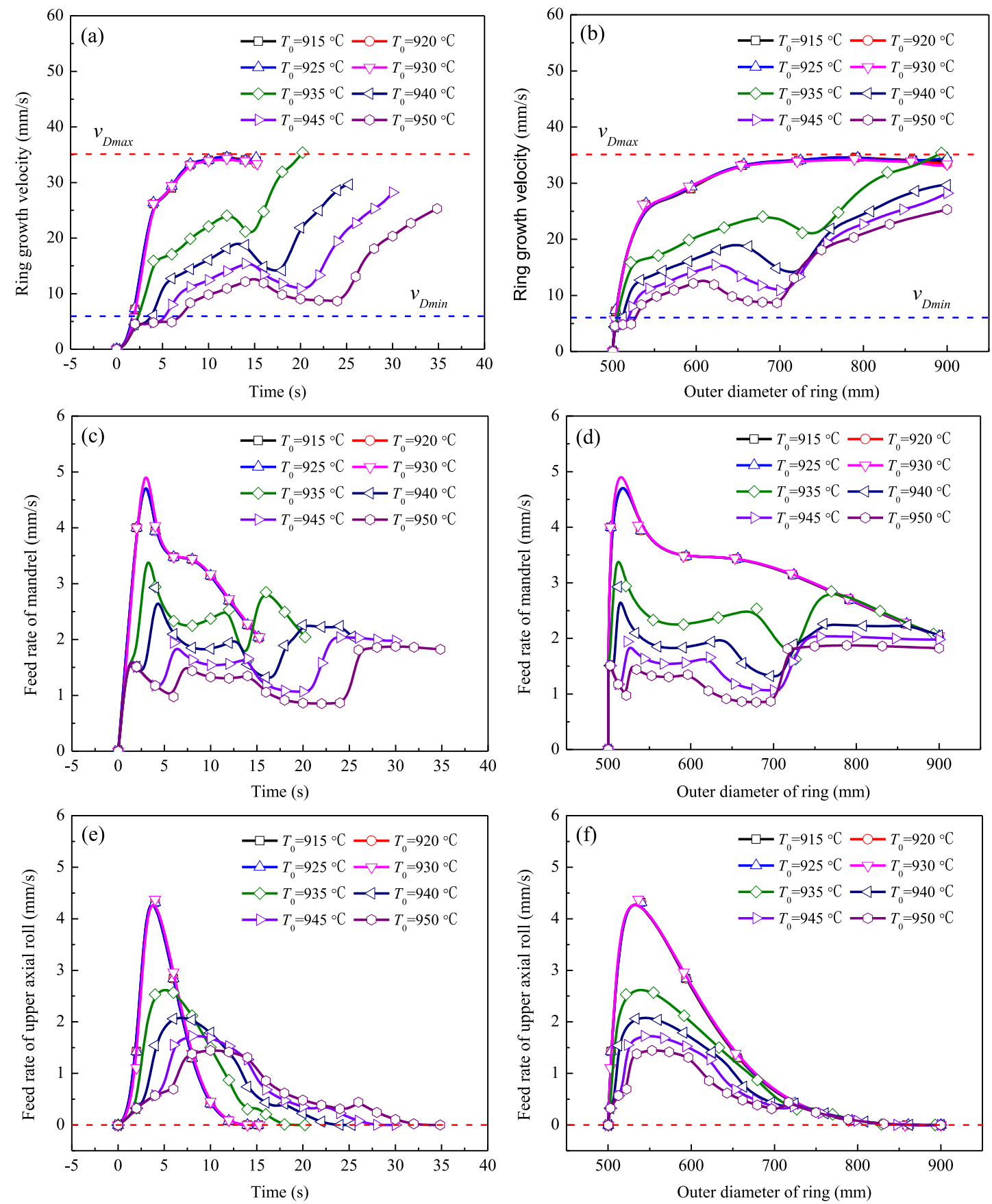

Fig. 5. Rolling paths designed by target-temperature driven intelligent simulation under different initial ring temperatures when $v_{D 0}=6 \mathrm{~mm} / \mathrm{s}$ : (a), (c) and (e) are ring growth velocity, feed rate of mandrel and feed rate of upper axial roll with time, respectively. (b), (d) and (f) are ring growth velocity, feed rate of mandrel and feed rate of upper axial roll with ring outer diameter, respectively.

Figures 5-7 show the designed rolling paths under different initial ring temperatures when the initial ring growth velocity $v_{D 0}$ is $6 \mathrm{~mm} / \mathrm{s}, 20 \mathrm{~mm} / \mathrm{s}$ and $35 \mathrm{~mm} / \mathrm{s}$, respectively. As analyzed above, the initial ring temperature $T_{0}$ and initial ring growth velocity $v_{D 0}$ are key parameters influencing the rolling paths. Therefore, the influence rule of $T_{0}$ and $v_{D 0}$ on the designed rolling paths will be discussed below.

\subsubsection{Influence rule of initial conditions on rolling paths}

Under the same initial ring growth velocity $v_{D 0}$, for the initial temperature of $915^{\circ} \mathrm{C}, 920^{\circ} \mathrm{C}, 925^{\circ} \mathrm{C}$ and $930^{\circ} \mathrm{C}$, the curves of ring growth velocity, feed rate of mandrel and feed rate of upper axial roll are almost coincident, as shown in Figures $5-7$. This is because the minimum temperature of ring $T_{\text {ring-min }}$ will be less than the lower limit of temperature 

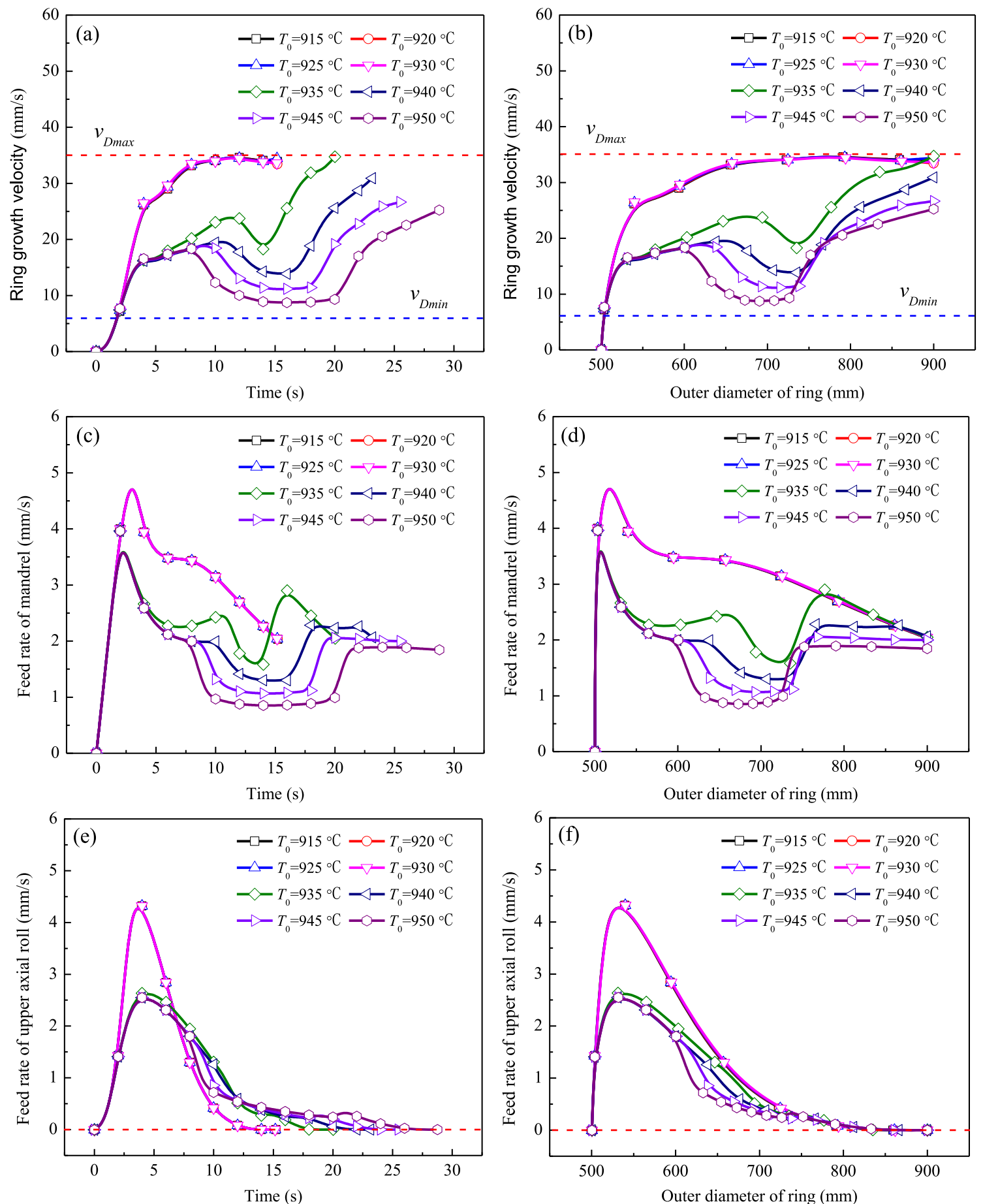

Fig. 6. Rolling paths designed by target-temperature driven intelligent simulation under different initial ring temperatures when $v_{D 0}=20 \mathrm{~mm} / \mathrm{s}$ : (a), (c) and (e) are ring growth velocity, feed rate of mandrel and feed rate of upper axial roll with time, respectively. (b), (d) and (f) are ring growth velocity, feed rate of mandrel and feed rate of upper axial roll with ring outer diameter, respectively.

control objective within a very short time when the initial ring temperature is too low. The ring growth velocity model $v_{D}=f_{3}\left(T_{\text {obj-min }}, D_{t}, T_{0}\right)$ will be employed to regulate the ring temperature. However, $v_{D}$ belongs to the case of no solution at this time. According to the ring growth velocity model in equation (5), to avoid further drop of the minimum temperature of ring, the maximum value of ring growth velocity $\left(v_{D \max }\right)$ determined by the gripping conditions is directly employed to adjust the motions of all rolls, thus generating more deformation heat for increasing the minimum temperature of ring as soon as possible. That is to say, the same ring growth velocity $\left(v_{D \max }\right)$ is employed for the initial temperature of $915^{\circ} \mathrm{C}$, $920^{\circ} \mathrm{C}, 925^{\circ} \mathrm{C}$ and $930^{\circ} \mathrm{C}$, thus leading to the same rolling 

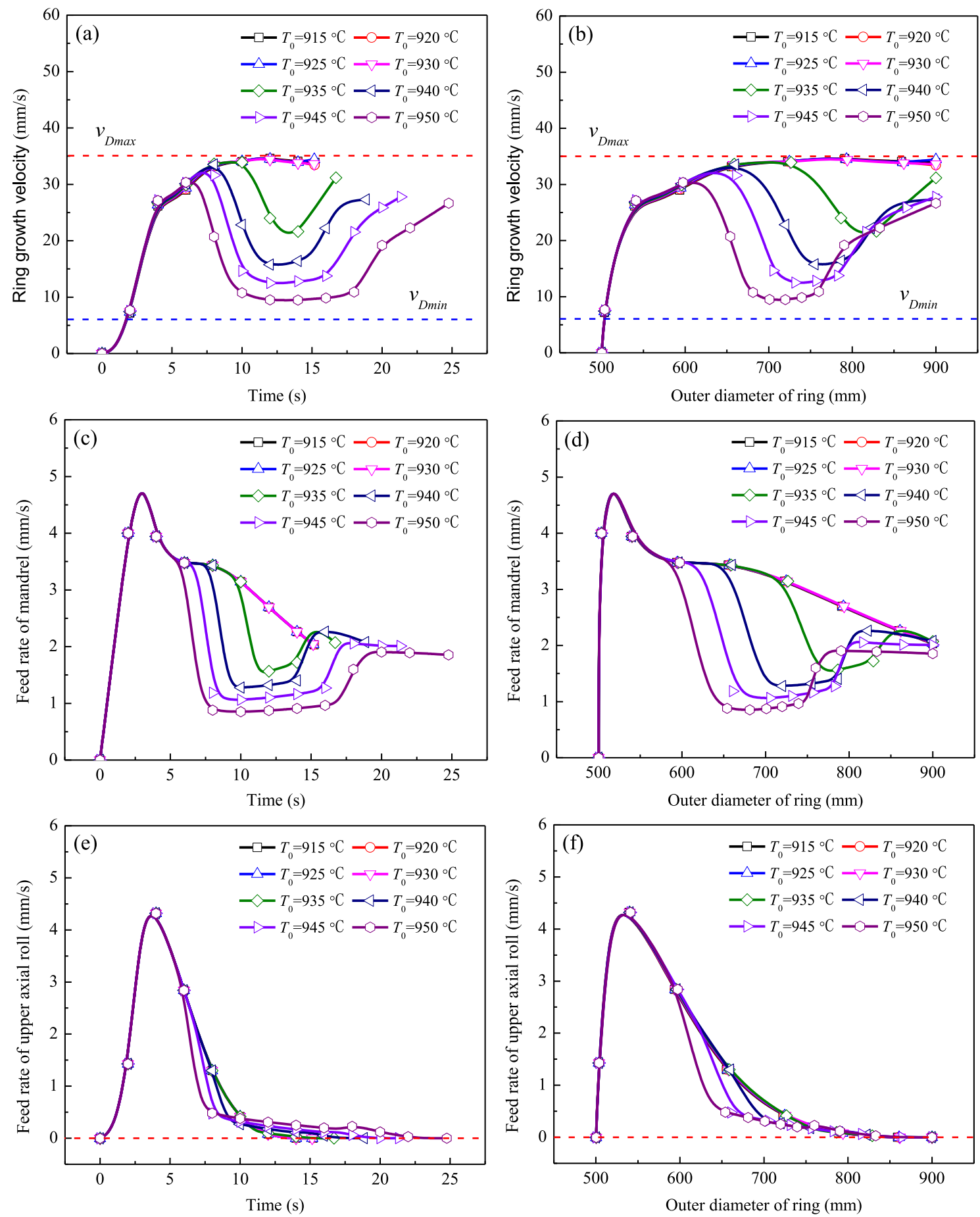

Fig. 7. Rolling paths designed by target-temperature driven intelligent simulation under different initial ring temperatures when $v_{D 0}=35 \mathrm{~mm} / \mathrm{s}$ : (a), (c) and (e) are ring growth velocity, feed rate of mandrel and feed rate of upper axial roll with time, respectively. (b), (d) and (f) are ring growth velocity, feed rate of mandrel and feed rate of upper axial roll with ring outer diameter, respectively.

paths. Therefore, the curves of ring growth velocity, feed rate of mandrel and feed rate of upper axial roll are almost coincident.

When the initial temperature of ring $T_{0}>930^{\circ} \mathrm{C}$, the ring growth velocity first increases then decreases and finally increases again. Driven by the ring growth velocity, the feed rates of mandrel and axial roll also change accordingly. This can be explained as follows: at the initial stage of rolling process, the minimum temperature of ring $T_{\text {ring-min }}$ drops below the lower limit of control objective $T_{\text {obj-min }}$, so the ring growth velocity increases to generate more deformation heat. Due to the increase of initial temperature of ring, the maximum temperature of ring $T_{\text {ring-max }}$ becomes easy to exceed the upper limit of control objective $T_{\text {obj-max }}$. To decrease the maximum temperature of ring, the ring growth velocity decreases to reduce the 
generation of plastic deformation heat. At last, the ring growth velocity increases again to maintain the minimum temperature of ring within the desired range.

In addition, when initial ring temperature $T_{0}>$ $930^{\circ} \mathrm{C}$, the variation trends of ring growth velocity and the feed rates of mandrel and axial roll under different initial ring temperatures are similar. However, with the increase of initial temperature of ring, the ring growth velocity and the feed rates of mandrel and axial roll decrease. This will lead to the rolling time becoming longer, thus reducing the heat generation and increasing the heat loss to maintain the ring temperature within the control objective.

Under different initial ring growth velocities $v_{D 0}$, the ring growth velocity shows a significant difference during the whole process. This agrees well with the analysis in Figure 3. The greater the initial ring growth velocity, the more deformation heat at the initial period of rolling process, resulting in the ring temperature being easier to exceed the upper limit of temperature control objective. Therefore, the ring growth velocity under $v_{D 0}=35 \mathrm{~mm} / \mathrm{s}$ first decreases to reduce the deformation heat. Moreover, the time under lower velocity becomes longer until the ring temperature meets the control objective. The feed rates of mandrel and upper axial roll also decrease accordingly. This eventually makes the rolling paths become different under different $v_{D 0}$.

In a word, according to different initial conditions $\left(T_{0}\right.$ and $\left.v_{D 0}\right)$, the ring growth velocity can be adjusted adaptively by tracing the temperature control objective during the target-temperature driven intelligent $\mathrm{FE}$ simulation. Driven by the ring growth velocity, the motions of mandrel and upper axial roll will also be adjusted accordingly. In the actual production, the ring growth velocity is the main parameter the ring rolling mill needs to input. If the ring growth velocity is determined, the rolling paths can be obtained. Therefore, the targettemperature driven intelligent simulation can realize the quick design for rolling paths in radial-axial ring rolling. Different rolling paths will lead to different deformation behaviors, thus influencing the temperature of ring. The temperature control effects under the designed rolling paths are discussed below.

\subsection{Temperature control effects under designed rolling paths}

\subsubsection{Temperature control effects}

In FE model, the ring is meshed by a total of 30240 elements. The temperatures of all the elements are sorted from high to low in each increment. Here, the temperature of the 29938 th element $(30240 \times 99 \%=29938)$ is defined as $T_{\text {ring-99\%. If }} T_{\text {ring-99\% }}$ is maintained above the lower limit of the control objective $T_{\text {obj-min }}$ during the whole process, it is indicated that the temperatures of ninety-nine percent elements have been controlled accurately. The minimum temperature mainly exists on the surface of ring, while the low temperature part of ring will be cut off during the subsequent machining process in actual production. This means the temperature control for this part almost can be neglected. Therefore, the ring temperature can be considered to meet the temperature control requirement during the whole process.

Different initial conditions will lead to great difference of rolling paths, so the temperature control effects under different initial ring temperatures $T_{0}$ and initial ring growth velocities $v_{D 0}$ are different. Figures 8-10 display the temperature control effects under different initial ring temperatures when initial ring growth velocity $v_{D 0}$ is $6 \mathrm{~mm} / \mathrm{s}, 20 \mathrm{~mm} / \mathrm{s}$ and $35 \mathrm{~mm} / \mathrm{s}$, respectively. The influence rule of initial conditions of $T_{0}$ and $v_{D 0}$ on temperature control effects is discussed below.

\subsubsection{Influence rule of initial conditions on temperature control effects}

Under the same initial ring growth velocity like $v_{D 0}=$ $6 \mathrm{~mm} / \mathrm{s}$ in Figure 8, the ring temperature cannot be accurately controlled under the rolling paths of $915^{\circ} \mathrm{C}$ and $950^{\circ} \mathrm{C}$. For $T_{0}=915^{\circ} \mathrm{C}$ in Figure $8 \mathrm{a}$, the minimum temperature of ring $T_{\text {ring-min }}$ drops rapidly below the lower limit of the control objective $T_{\text {obj-min }}$. Driven by the ring growth velocity model, the ring growth velocity increases to generate more deformation heat. However, the generated plastic deformation heat is not enough to compensate for the temperature drop because the initial temperature is too low, leading to $T_{\text {ring-99\% }}$ being lower than $T_{\text {obj-min }}$ during almost the whole process. Therefore, the ring temperature cannot meet the control objective. For $T_{0}=950{ }^{\circ} \mathrm{C}$ in Figure $8 \mathrm{~h}$, the maximum temperature of ring $T_{\text {ring-max }}$ cannot be reduced in time because the initial temperature is too high, leading to longer time (larger than $10 \mathrm{~s}$ ) above the upper limit of control objective $T_{\text {obj-max }}$. Due to the lower ring growth velocity during the whole process, the rolling time increases, resulting in a great increase of heat loss. This makes the deviation value of $T_{\text {ring- } 99 \%}$ from $T_{\text {obj-min }}$ is relatively large (greater than $10^{\circ} \mathrm{C}$ ) at the end of rolling process. This means that the control effects of ring temperature are not satisfactory under the rolling paths when $T_{0}$ equals to $950^{\circ} \mathrm{C}$.

For the initial ring temperature of $920^{\circ} \mathrm{C}, 925^{\circ} \mathrm{C}$ and $930^{\circ} \mathrm{C}$ in Figure $8 \mathrm{~b}-\mathrm{d}$, the ring growth velocity rises rapidly to increase the deformation heat when the minimum temperature of ring $T_{\text {ring-min }}$ is lower than the lower limit of temperature control objective $T_{\text {obj-min }}$, which eventually maintains the minimum temperature of ring near the lower limit of control objective. However, with the increase of ring outer diameter, the rotational speed of ring becomes slower and the time interval passing through the deformation zones increases. Owing to the increase of heat dissipation area, the heat loss to ambient increases. The temperature drop can't be compensated by the deformation heat due to the lower initial temperature and the more heat loss. The minimum temperature of ring $T_{\text {ring-min }}$ drops continuously at the end of rolling process. However, $T_{\text {ring-99\% }}$ has been maintained above the lower limit of control objective $T_{\text {obj-min }}$. Therefore, the ring temperature could meet the temperature control objective under the rolling paths when $T_{0}$ equals to $920^{\circ} \mathrm{C}, 925^{\circ} \mathrm{C}$ and $930^{\circ} \mathrm{C}$. 

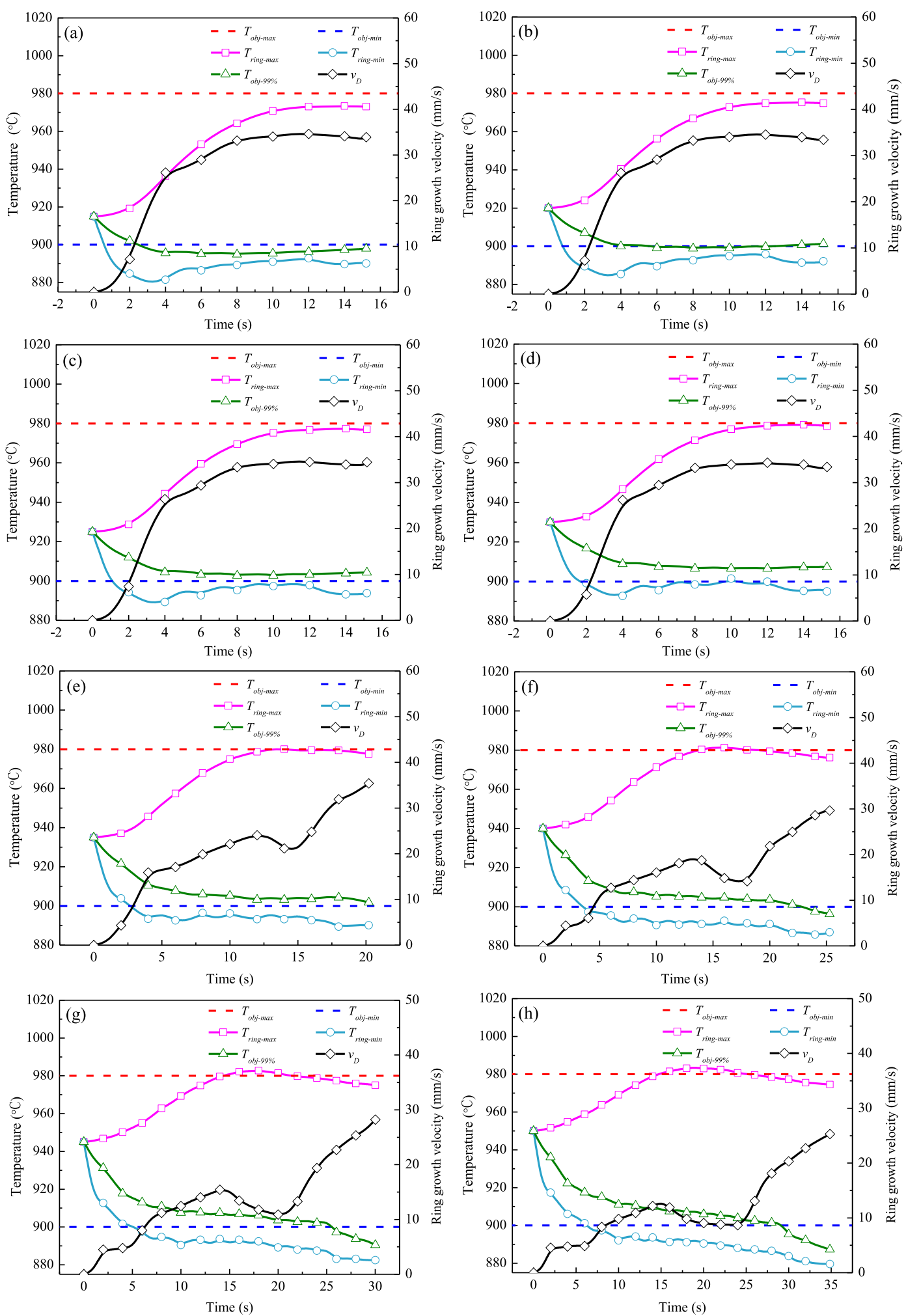

Fig. 8. Control effects of ring temperature under designed rolling paths when $v_{D 0}=6 \mathrm{~mm} / \mathrm{s}$ : (a) $T_{0}=915^{\circ} \mathrm{C} ;(\mathrm{b}) T_{0}=920^{\circ} \mathrm{C}$; (c) $T_{0}=925^{\circ} \mathrm{C}$; (d) $T_{0}=930^{\circ} \mathrm{C}$; (e) $T_{0}=935^{\circ} \mathrm{C}$; (f) $T_{0}=940{ }^{\circ} \mathrm{C}$; (g) $T_{0}=945^{\circ} \mathrm{C}$; (h) $T_{0}=950{ }^{\circ} \mathrm{C}$.

For the initial ring temperature of $935^{\circ} \mathrm{C}, 940{ }^{\circ} \mathrm{C}$ and $945^{\circ} \mathrm{C}$ in Figure $8 \mathrm{e}-\mathrm{g}$, the ring growth velocity increases to avoid the further decrease of the minimum temperature of ring at the early stage of ring rolling. However, the maximum temperature of ring $T_{\text {ring-max }}$ exceeds the upper limit of control objective $T_{\text {obj-max }}$ due to the higher initial temperature and the accumulation of deformation heat in the ring. Drive by the ring growth velocity model, the ring 

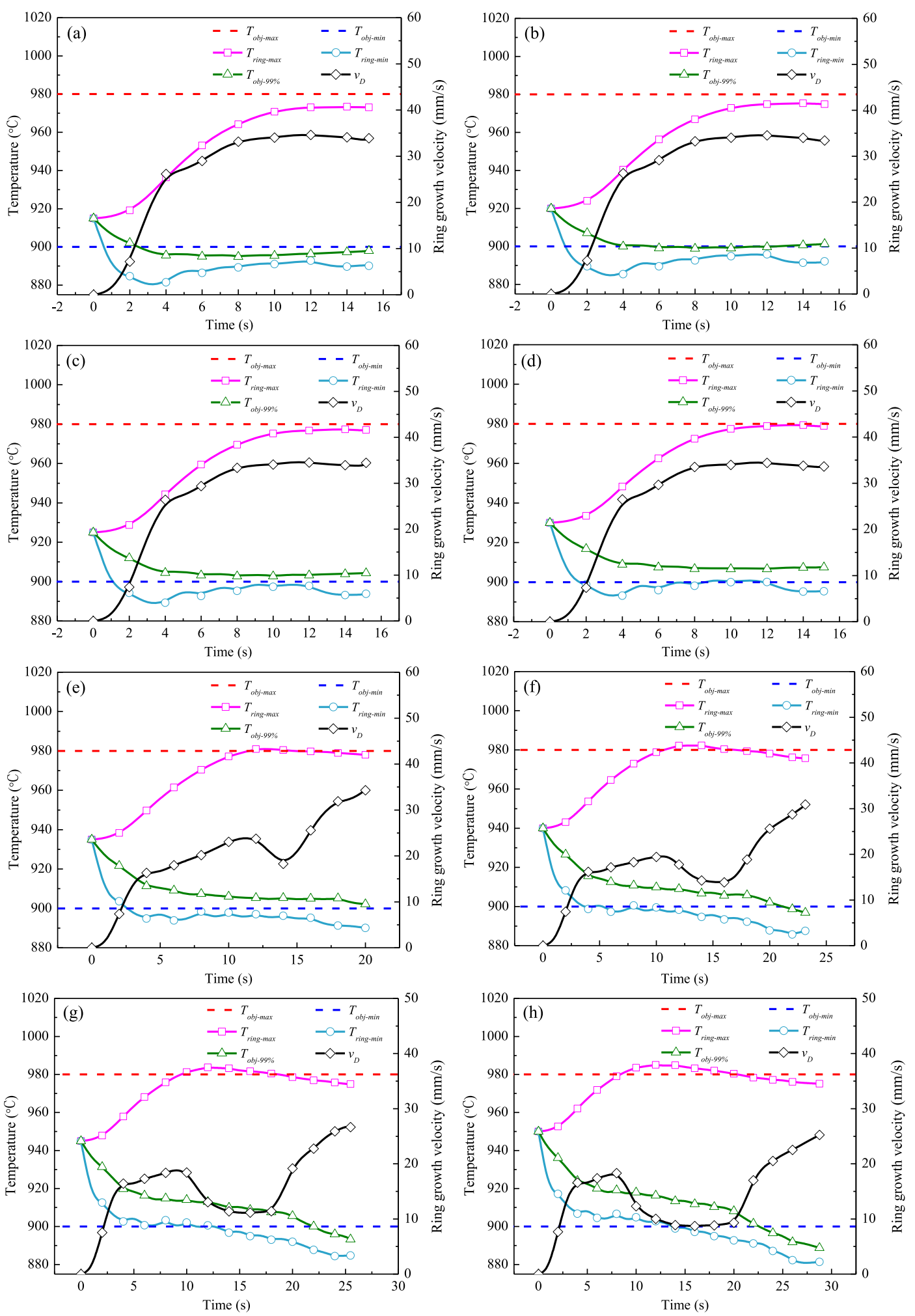

Fig. 9. Control effects of ring temperature under designed rolling paths when $v_{D 0}=20 \mathrm{~mm} / \mathrm{s}$ : (a) $T_{0}=915^{\circ} \mathrm{C} ;(\mathrm{b}) T_{0}=920^{\circ} \mathrm{C}$; (c) $T_{0}=925^{\circ} \mathrm{C}$; (d) $T_{0}=930{ }^{\circ} \mathrm{C}$; (e) $T_{0}=935^{\circ} \mathrm{C}$; (f) $T_{0}=940{ }^{\circ} \mathrm{C}$; (g) $T_{0}=945^{\circ} \mathrm{C}$; (h) $T_{0}=950{ }^{\circ} \mathrm{C}$.

growth velocity decreases to reduce the generation of deformation heat. When the generated deformation heat is less than heat loss to ambient, the maximum temperature of ring $T_{\text {ring-max }}$ starts to decrease until $T_{\text {ring-max }}$ meets the temperature control objective. After this, to raise the minimum temperature of ring $T_{\text {ring-min }}$, the ring growth velocity increases again. This means the ring growth velocity realizes the intelligent control for both the 

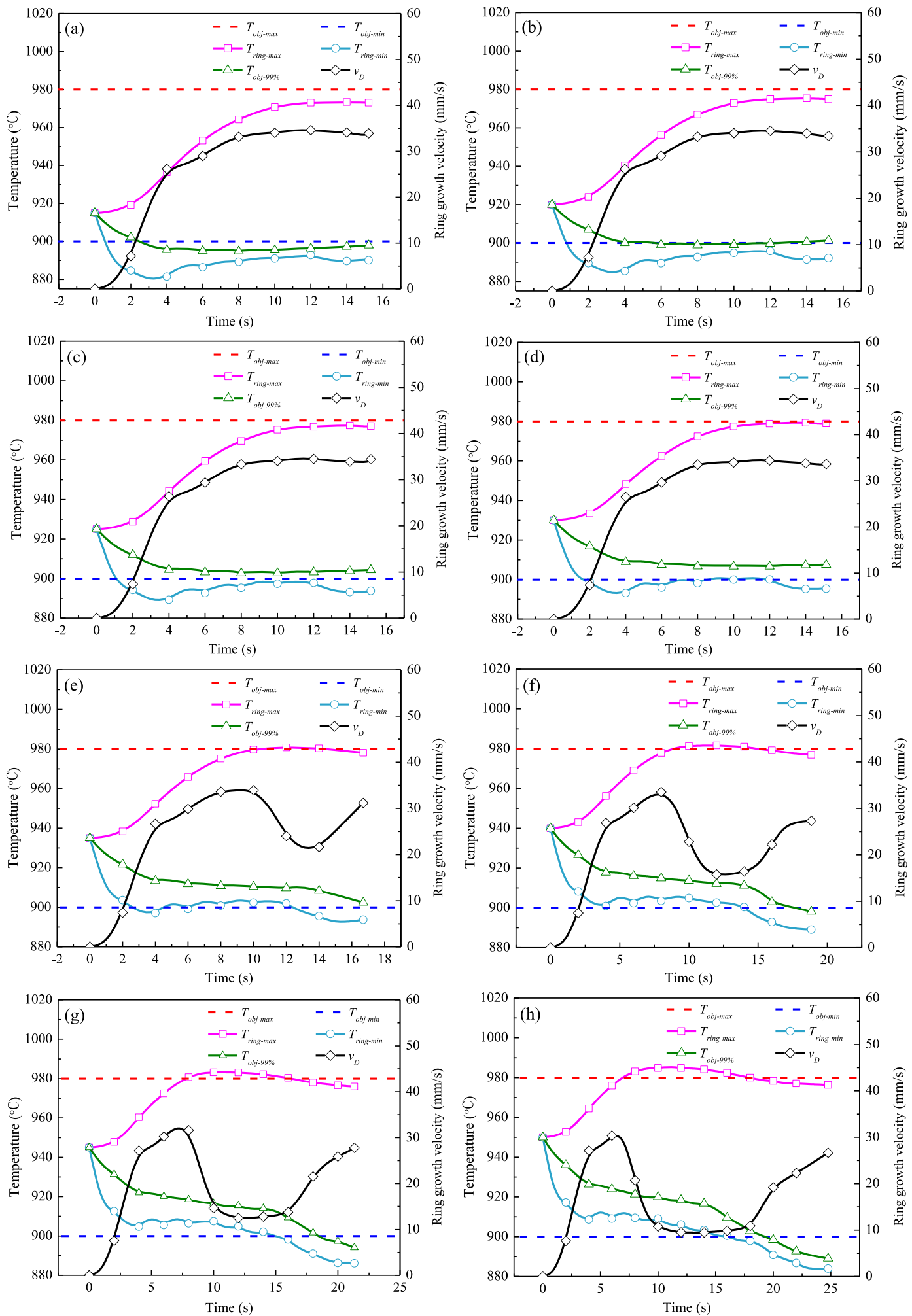

Fig. 10. Control effects of ring temperature under designed rolling paths when $v_{D 0}=35 \mathrm{~mm} / \mathrm{s}$ : (a) $T_{0}=915^{\circ} \mathrm{C} ;(\mathrm{b}) T_{0}=920^{\circ} \mathrm{C}$; (c) $T_{0}=925^{\circ} \mathrm{C}$; (d) $T_{0}=930{ }^{\circ} \mathrm{C}$; (e) $T_{0}=935^{\circ} \mathrm{C}$; (f) $T_{0}=940{ }^{\circ} \mathrm{C}$; (g) $T_{0}=945^{\circ} \mathrm{C}$; (h) $T_{0}=950{ }^{\circ} \mathrm{C}$.

minimum and maximum temperatures. Besides, $T_{\text {ring-99\% }}$ is maintained above the lower limit of temperature control objective almost in the whole process, especially for $935^{\circ} \mathrm{C}$. Though $T_{\text {ring- } 99 \%}$ when $T_{0}$ equals to $940^{\circ} \mathrm{C}$ and $945^{\circ} \mathrm{C}$ is lower than $T_{\text {obj-min }}$ due to more heat loss to ambient, the temperature deviation value is quite small (less than $10^{\circ} \mathrm{C}$ ). Therefore, the temperature control effects under the rolling paths when initial temperature $T_{0}$ equals to $935^{\circ} \mathrm{C}, 940^{\circ} \mathrm{C}$ and $945^{\circ} \mathrm{C}$ are considered acceptable. 
(a)
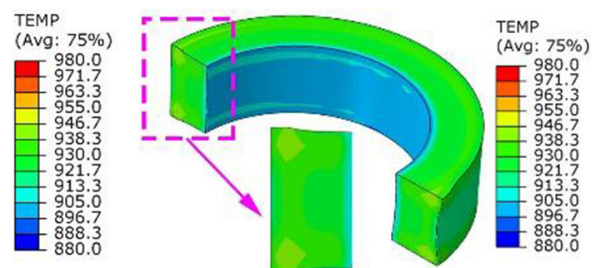

$$
\mathrm{t}=5 \mathrm{~s}
$$

(b) TEMP
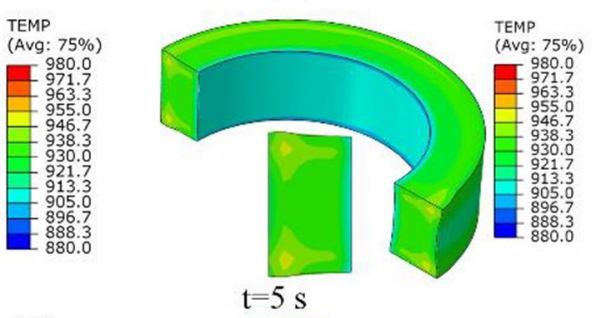

(c)

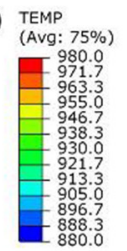

(d)
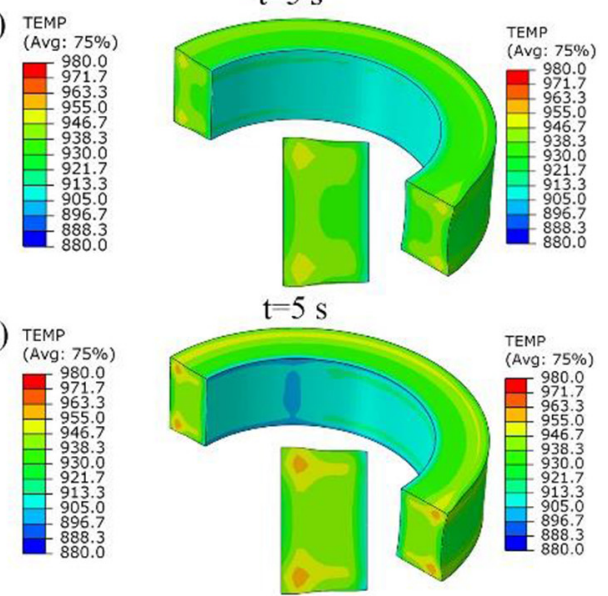

(e) TEMP

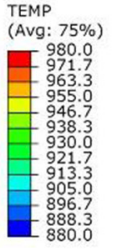

(f)

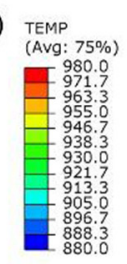

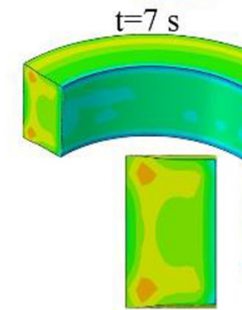

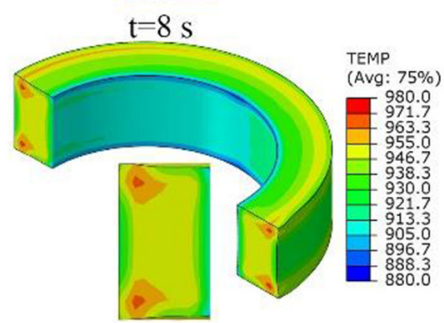

$\mathrm{t}=10 \mathrm{~s}$

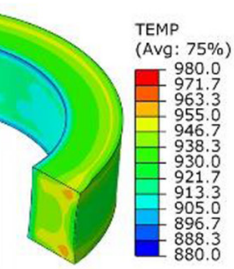

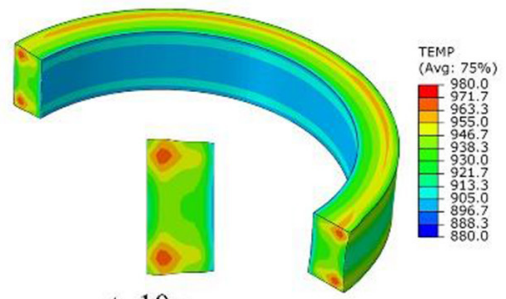

$\mathrm{t}=10 \mathrm{~s}$
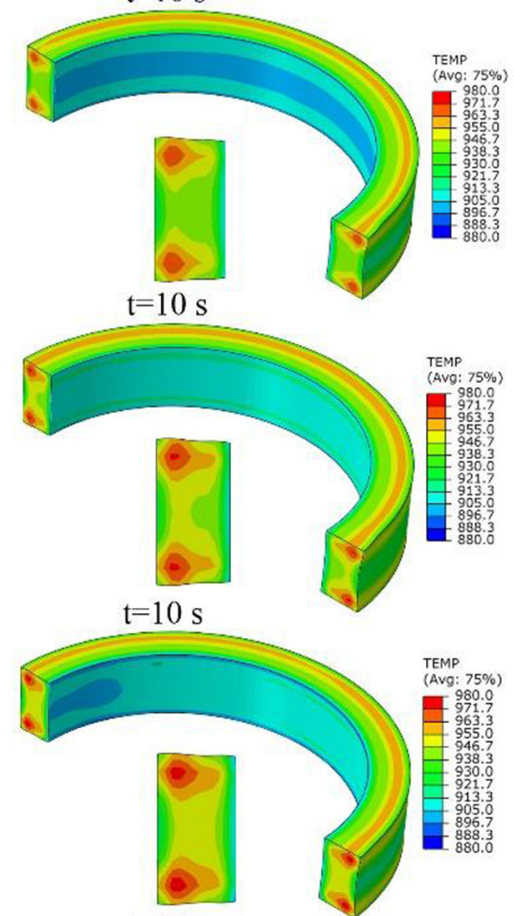

$\mathrm{t}=14 \mathrm{~s}$
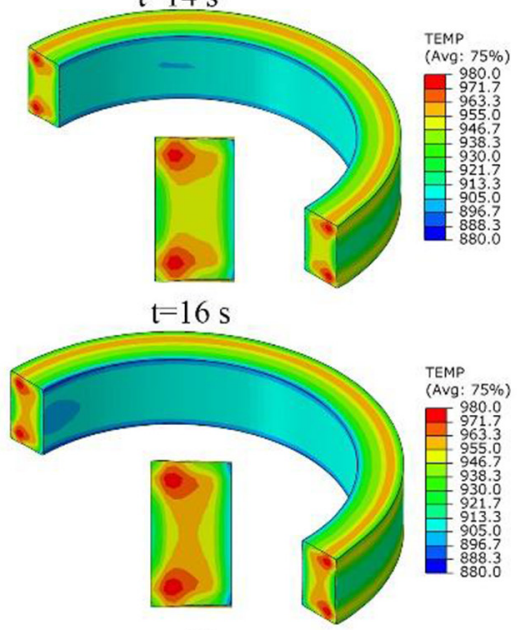

$t=20 s$

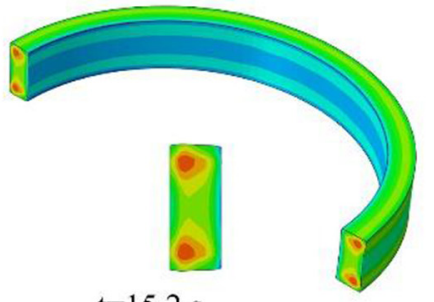

$\mathrm{t}=15.2 \mathrm{~s}$

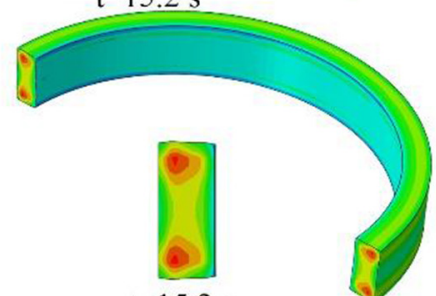

$\mathrm{t}=15.2 \mathrm{~s}$

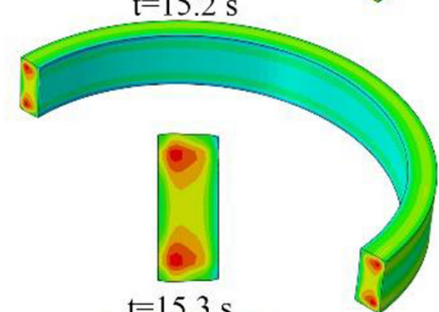

$\mathrm{t}=15.3 \mathrm{~s}$
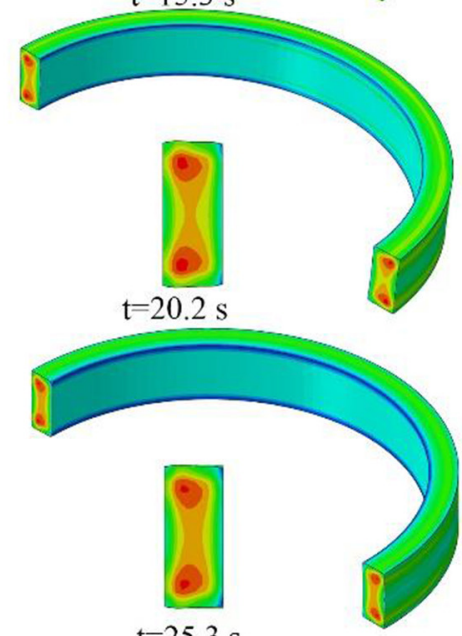

$\mathrm{t}=25.3 \mathrm{~s}$

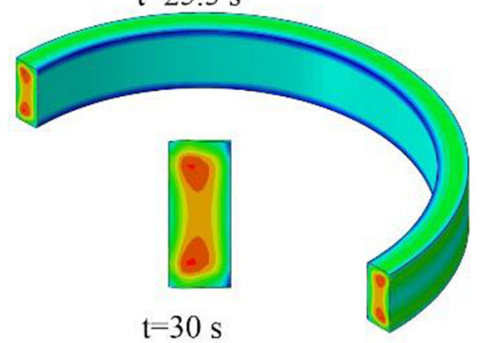

Fig. 11. Temperature evolution under designed rolling paths when $v_{D 0}=6 \mathrm{~mm} / \mathrm{s}$ : (a) $T_{0}=920^{\circ} \mathrm{C} ;(\mathrm{b}) T_{0}=925^{\circ} \mathrm{C} ;(\mathrm{c}) T_{0}=930^{\circ} \mathrm{C}$; (d) $T_{0}=935^{\circ} \mathrm{C}$; (e) $T_{0}=940^{\circ} \mathrm{C}$; (f) $T_{0}=945^{\circ} \mathrm{C}$.

From Figures 8-10, under different initial ring growth velocities $v_{D 0}$, the similar conclusions can be obtained. For the initial temperature of $915^{\circ} \mathrm{C}$ and $950{ }^{\circ} \mathrm{C}$, the ring temperature cannot be accurately maintained within the desired range under the corresponding rolling paths. For the initial temperature of $920^{\circ} \mathrm{C}-945^{\circ} \mathrm{C}$, it is considered that the control effects of ring temperature are all satisfactory under the corresponding rolling paths. It is revealed that initial temperature $T_{0}$ exists a feasible range of $920^{\circ} \mathrm{C}-945^{\circ} \mathrm{C}$ for realizing the intelligent control of ring temperature. Within this feasible range, as long as the initial ring growth velocity $v_{D 0}$ meets the gripping and 
(a)
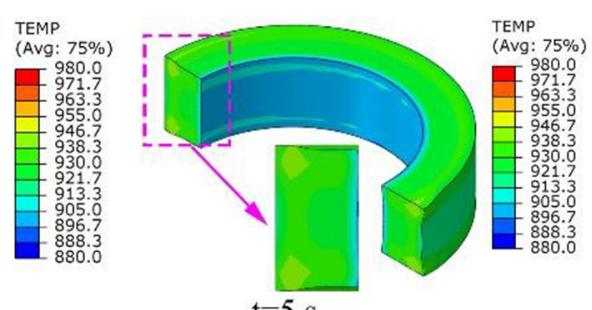

(b)
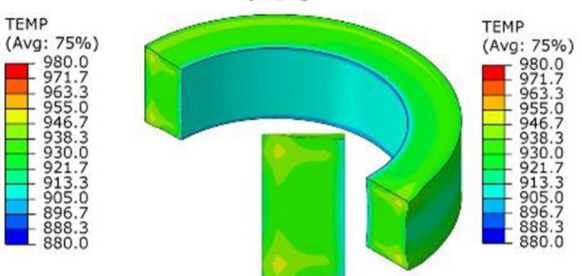

(c)
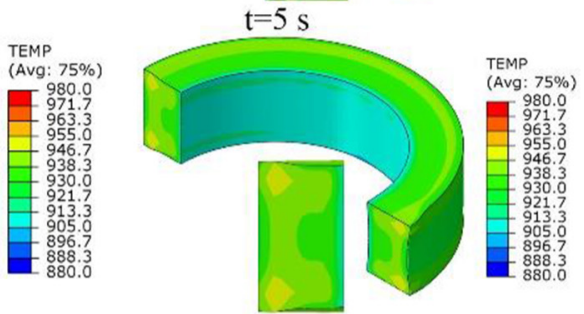

(d)
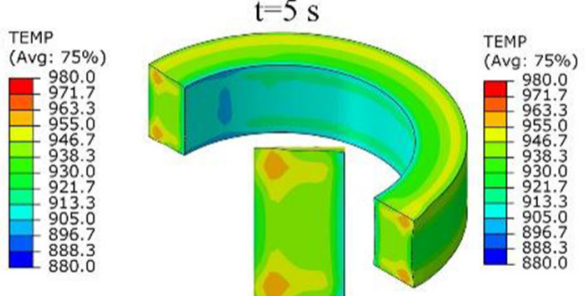

(e) TEMP

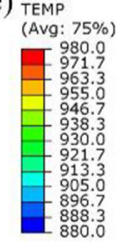

(f)

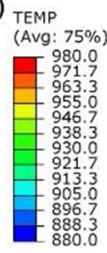

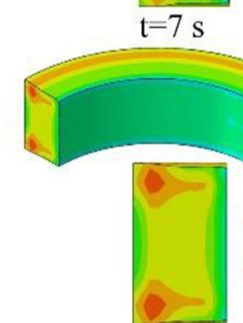

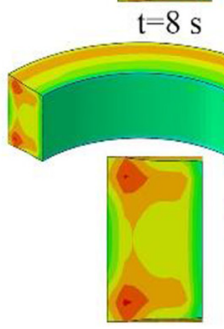

$\mathrm{t}=8 \mathrm{~s}$

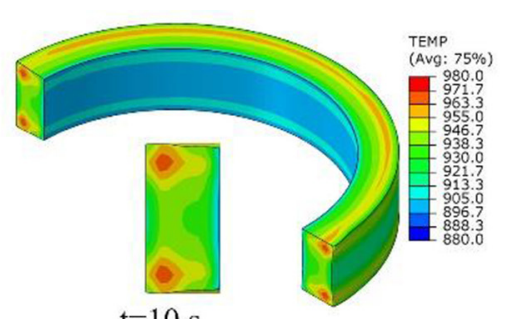

$\mathrm{t}=10 \mathrm{~s}$
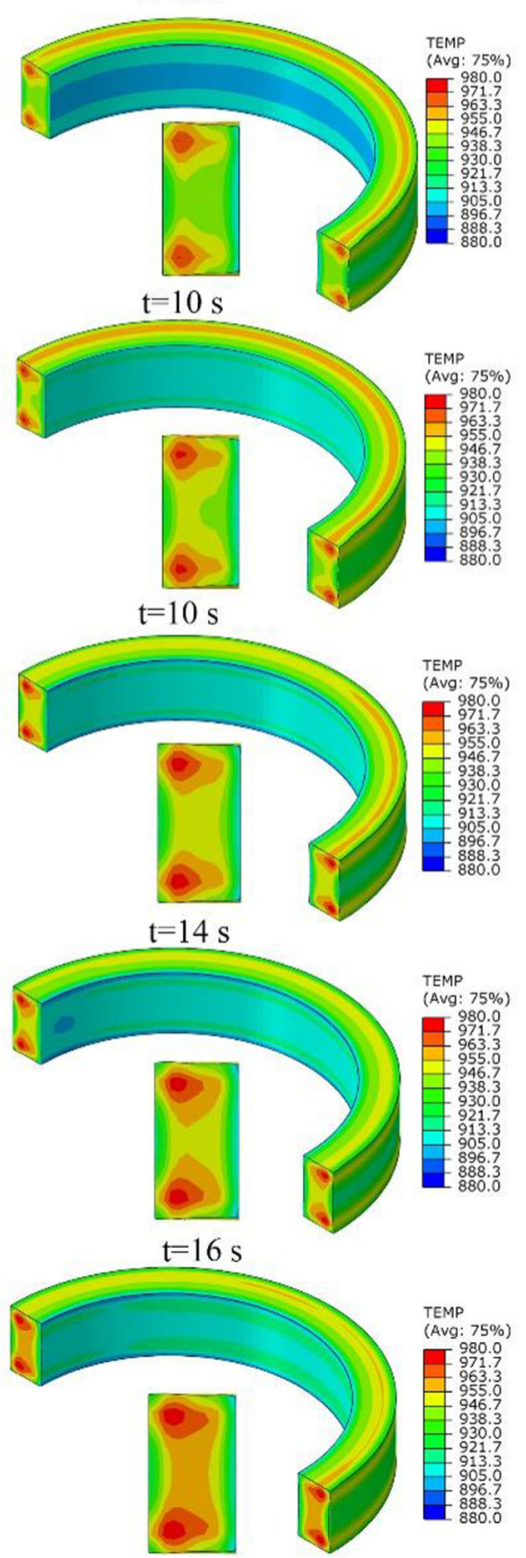

$t=16 s$

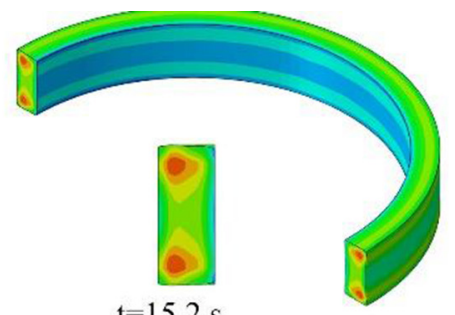

$\mathrm{t}=15.2 \mathrm{~s}$
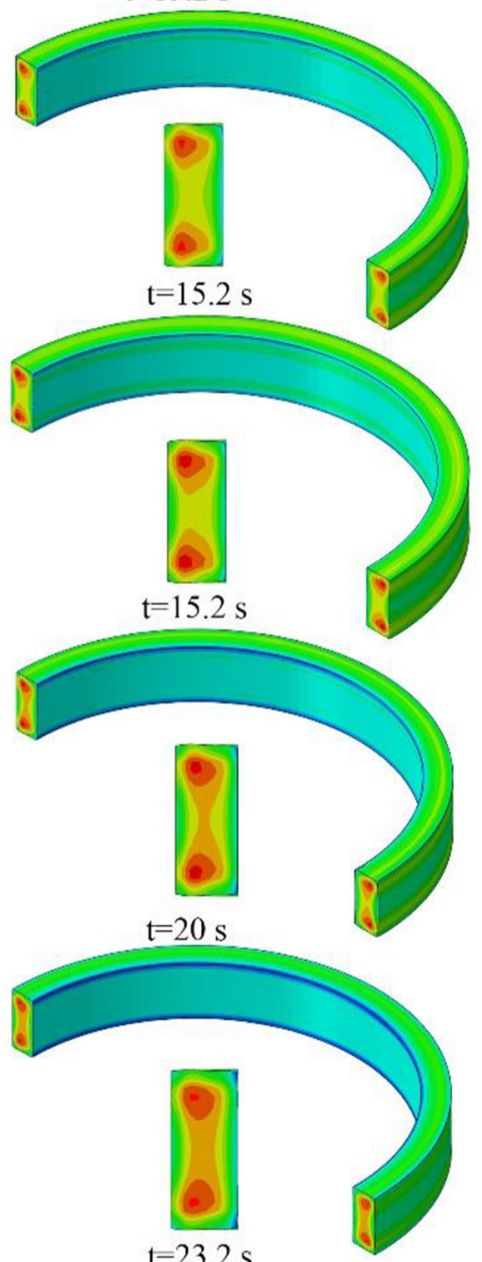

$\mathrm{t}=23.2 \mathrm{~s}$

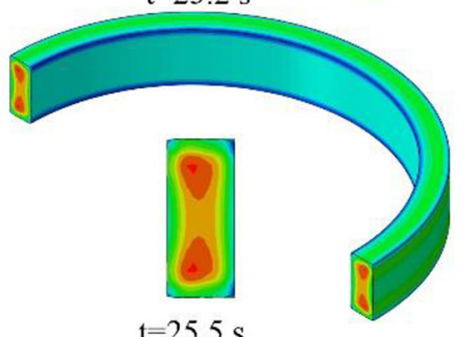

Fig. 12. Temperature evolution under designed rolling paths when $v_{D 0}=20 \mathrm{~mm} / \mathrm{s}$ : (a) $T_{0}=920^{\circ} \mathrm{C} ;(\mathrm{b}) T_{0}=925^{\circ} \mathrm{C} ;(\mathrm{c}) T_{0}=930^{\circ} \mathrm{C}$; (d) $T_{0}=935^{\circ} \mathrm{C}$; (e) $T_{0}=940^{\circ} \mathrm{C}$; (f) $T_{0}=945^{\circ} \mathrm{C}$.

penetrating conditions, the ring temperature can be controlled within the desired range. This provides an important reference for the determination of initial temperature of ring in actual production of ring rolling of TA15 titanium alloy.
However, as discussed above, different initial ring growth velocities affect the rolling paths, thus leading to the difference of ring temperature control effects. From Figures 8-10, under different initial ring growth velocities and the same initial temperature of ring, the higher the 
(a)
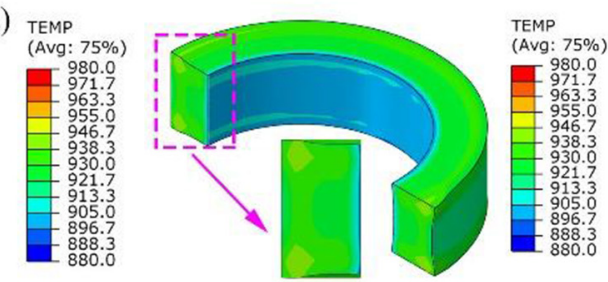

$$
\mathrm{t}=5 \mathrm{~s}
$$

(b) TEMP

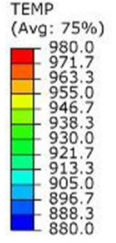

(c) TEMP

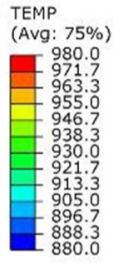

(d)

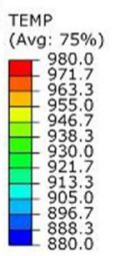

(e)

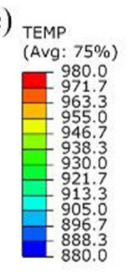

(f)

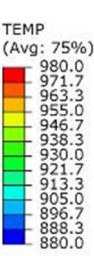

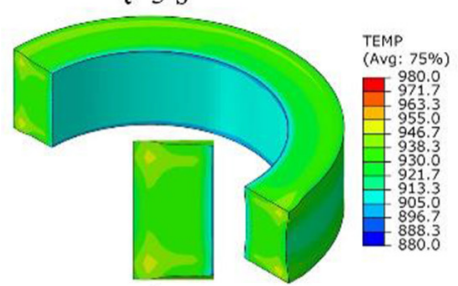
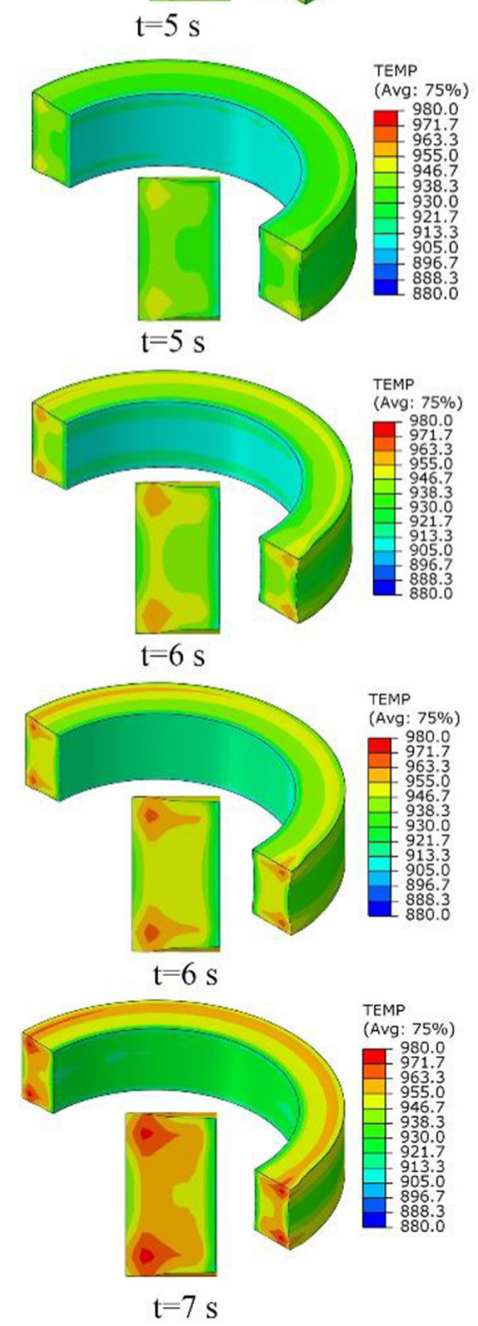

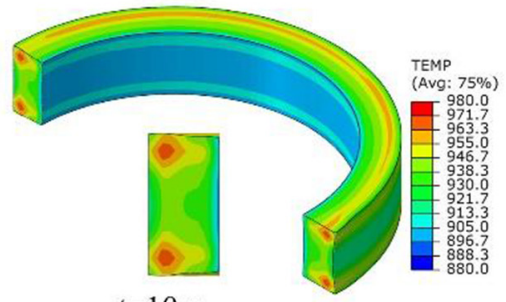

$\mathrm{t}=10 \mathrm{~s}$
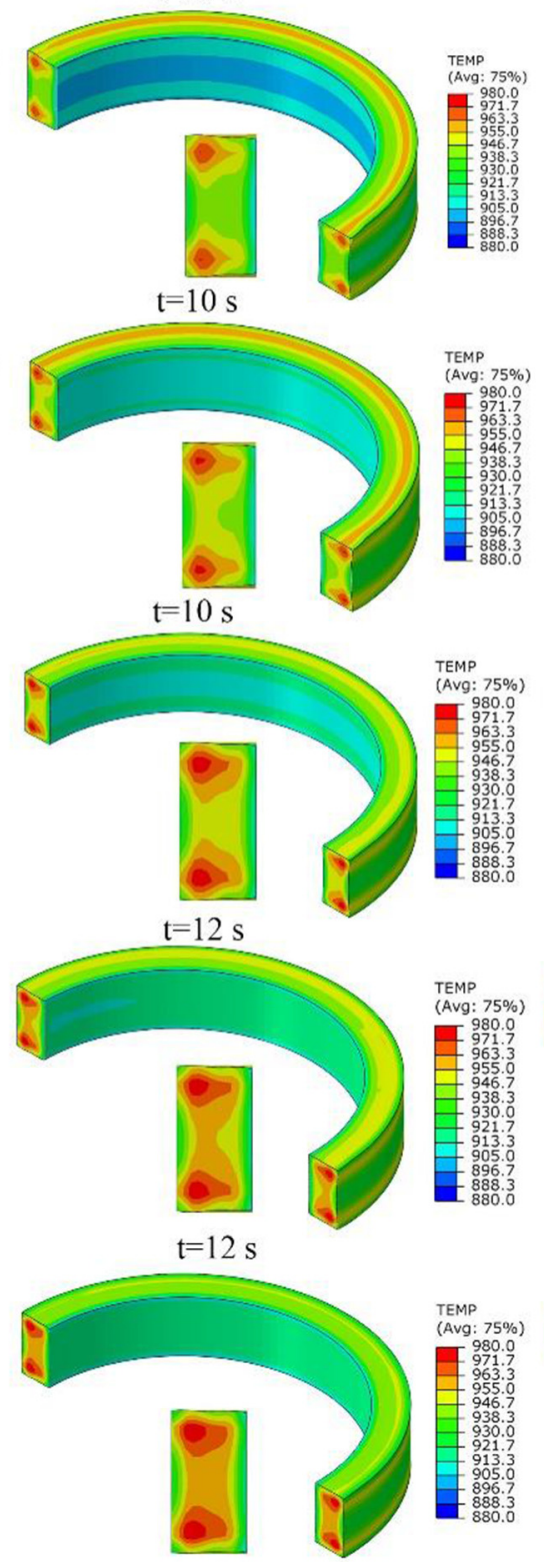

$\mathrm{t}=14 \mathrm{~s}$
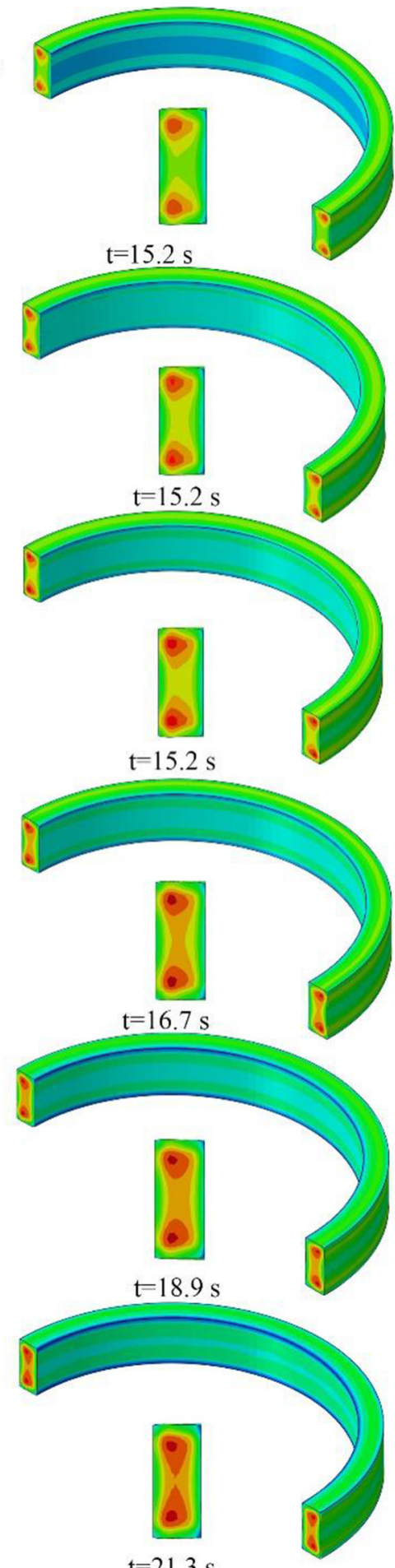

Fig. 13. Temperature evolution under designed rolling paths when $v_{D 0}=35 \mathrm{~mm} / \mathrm{s}$ : (a) $T_{0}=920{ }^{\circ} \mathrm{C} ;(\mathrm{b}) T_{0}=925^{\circ} \mathrm{C} ;(\mathrm{c}) T_{0}=930{ }^{\circ} \mathrm{C}$; (d) $T_{0}=935{ }^{\circ} \mathrm{C}$; (e) $T_{0}=940{ }^{\circ} \mathrm{C}$; (f) $T_{0}=945^{\circ} \mathrm{C}$.

initial value of ring growth velocity $v_{D 0}$, the earlier the maximum temperature of ring $T_{\text {ring-max }}$ exceeds the upper limit of the control objective $T_{\text {obj-max }}$ due to the fast accumulation of plastic deformation heat and the less heat loss. Driven by the ring growth velocity model, the subsequent ring growth velocity decreases early to reduce the deformation heat. The lower the initial value of ring growth velocity $v_{D 0}$, the earlier the minimum temperature of ring $T_{\text {ring-min }}$ is less than the lower limit of the control objective $T_{\text {obj-min }}$ due to the less plastic deformation heat 
and the more heat loss. The subsequent ring growth velocity increases early to avoid further temperature drop with the driving of ring growth velocity model.

\subsubsection{Temperature evolution under designed rolling paths}

To further study the temperature distribution and temperature control effects under the designed rolling paths, Figures 11-13 display the temperature evolution with rolling time under the rolling paths which could realize accurate temperature control when $v_{D 0}=6 \mathrm{~mm} / \mathrm{s}, 20 \mathrm{~mm} / \mathrm{s}$ and $35 \mathrm{~mm} / \mathrm{s}$, respectively.

Obviously, the low temperature region is mainly distributed on the surface of ring due to its direct heat transfer behavior with the rolls and external environment. The temperature inside the ring is relatively higher than other regions owing to the less heat loss.

From Figures 11-13, under the same initial ring growth velocity, for the initial ring temperature of $920^{\circ} \mathrm{C}, 925^{\circ} \mathrm{C}$ and $930^{\circ} \mathrm{C}$, the maximum temperature of ring $T_{\text {ring-max }}$ increases gradually with the rolling time, which can be attributed to the continuous accumulation of plastic deformation heat caused by the increase of ring growth velocity. The minimum temperature of ring $T_{\text {ring-min }}$ first increases and then decreases at the late stage of rolling process, which is in good agreement with the results obtained in Section 3.2.2.

For the initial ring temperature of $935^{\circ} \mathrm{C}, 940^{\circ} \mathrm{C}$ and $945^{\circ} \mathrm{C}$, the maximum temperature of ring $T_{\text {ring-max }}$ first increases and then decreases with the rolling time. As discussed above, the maximum temperature of ring $T_{\text {ring-max }}$ is easy to exceed the upper limit of temperature control objective $T_{\text {obj-max }}$ when the initial ring temperature $T_{0}$ is higher. The ring growth velocity will decrease to reduce the deformation heat at this time. With the effect of intelligent control of rolling paths, the maximum temperature of ring $T_{\text {ring-max }}$ is maintained below the upper limit of temperature control objective $T_{\text {obj-max }}$. For the minimum temperature of ring, only the temperature in the ring corner becomes less than the lower limit of temperature control objective $T_{\text {obj-min }}$. This indicates that the ring temperature can be maintained within the desired range of $900-980^{\circ} \mathrm{C}$ throughout the ring rolling process.

Besides, from Figures 11-13, it can be seen that all the rings keep a high geometric quality during the targettemperature driven intelligent simulation of radial-axial ring rolling process. The rolled rings with higher circularity are obtained, which reveals that the whole rolling process can maintain a higher stability under the effect of rolling paths designed by target-temperature driven intelligent FE simulation.

The analysis above indicates not only the ring temperature can be controlled within the reasonable range, but the whole rolling process can keep a higher stability, using the target-temperature driven intelligent FE simulation. This means the reasonable rolling paths which could realize intelligent temperature control and ensure process stability simultaneously can be designed directly only by one intelligent simulation. The obtained results could provide a meaningful reference for the design and optimization of rolling paths and accurate regulation of ring temperature in the actual industrial production of ring rolling, thus greatly improving the production efficiency and the quality of rolled ring.

\section{Conclusions}

Through target-temperature driven intelligent FE simulation, this work proposes a method for designing the rolling paths which could realize accurate control of the ring temperature. The main conclusions are drawn as follows: - The main idea of target-temperature driven intelligent simulation is introduced. In this idea, the initial ring temperature $T_{0}$ and initial ring growth velocity $v_{D 0}$ are two key parameters influencing the rolling paths. By VUAMP subroutine development, an intelligent 3D-FE model for TA15 titanium alloy ring rolling is established under ABAQUS/Explicit environment.

- By target-temperature driven intelligent simulations, the rolling paths under different initial conditions $\left(T_{0}\right.$ and $\left.v_{D 0}\right)$ are obtained, and the influence rule of $T_{0}$ and $v_{D 0}$ on rolling paths is revealed. The higher the initial ring temperature $T_{0}$, the smaller the ring growth velocity $v_{D}$. The greater the initial ring growth velocity $v_{D 0}$, the earlier the ring growth velocity $v_{D}$ decreases. This method could realize the quick and accurate design for the rolling paths in radial-axial ring rolling process.

- The temperature control effects under the designed rolling paths are discussed and the influence rule of $T_{0}$ and $v_{D 0}$ on temperature control effects is revealed. The simulation results indicate the ring temperature could be maintained within the desired range when the initial ring temperature $T_{0}$ is within the feasible range of $920-945^{\circ} \mathrm{C}$. This provides a meaningful reference for accurate regulation of ring temperature in the actual production.

The authors would like to thank the support of the National Natural Science Foundation of China (No. 51575448, 51875468) and the Research \& Development Institute of Northwestern Polytechnical University in Shenzhen (JCYJ20170815162709770).

\section{References}

1. R. M'Saoubi, C. Nobel, W.M. Sim, High performance cutting of advanced aerospace alloys and composite materials, CIRP Ann. Manuf. Technol. 64 (2015) 557-580

2. S. Zhu, H. Yang, L.G. Guo et al., Effect of cooling rate on microstructure evolution during $\alpha / \beta$ heat treatment of TA15 titanium alloy, Mater. Char. 70 (2012) 101-110

3. P.F. Gao, H. Yang, X.G. Fan et al., Microstructure evolution in the local loading forming of TA15 titanium alloy under non-isothermal condition [J], J. Mater. Process. Technol. 212 (2012) 2520-2528

4. D. He, J. Zhu, S. Zaefferer et al., Effect of retained beta layer on slip transmission in Ti-6Al-2Zr-1Mo-1V near alpha titanium alloy during tensile deformation at room temperature, Mater. Des. 56 (2014) 937-942

5. J.M. Allwood, A.E. Tekkaya, T.F. Stanistreet, The development of ring rolling technology, Steel Res. Int. 76 (2005) $111-120$ 
6. H. Yang, M. Wang, L.G. Guo et al., 3D coupled thermomechanical FE modeling of blank size effects on the uniformity of strain and temperature distributions during hot rolling of titanium alloy large rings, Comput. Mat. Sci. 44 (2009) 611-621

7. S. Zhu, H. Yang, L. Guo et al., Research on the effects of coordinate deformation on radial-axial ring rolling process by FE simulation based on in-process control, Int. J. Adv. Manuf. Technol. 72 (2014) 57-68

8. Z. Sun, H. Yang, X. Ou, Effects of process parameters on microstructural evolution during hot ring rolling of AISI 5140 steel, Comput. Mater. Sci. 49 (2010) 134-142

9. G. Zhou, L. Hua, J. Lan et al., FE analysis of coupled thermomechanical behaviors in radial-axial rolling of alloy steel large ring, Comput. Mater. Sci. 50 (2010) 65-76

10. X. Tang, B. Wang, H. Zhang et al., Study on the microstructure evolution during radial-axial ring rolling of IN718 using a unified internal state variable material model, Int. J. Mech. Sci. 128 (2017) 235-252

11. S.L. Semiatin, S.L. Knisley, P.N. Fagin et al., Microstructure evolution during alpha-beta heat treatment of Ti-6Al-4V, Metal. Mater. Trans. A 34 (2003) 2377-2386

12. Y.G. Zhou, W.D. Zeng, H.Q. Yu, An investigation of a new near-beta forging process for titanium alloys and its application in aviation components, Mater. Sci. Eng. A 393 (2005) 204-212

13. X.G. Fan, H. Yang, P.F. Gao, Through-process macromicro finite element modeling of local loading forming of large-scale complex titanium alloy component for microstructure prediction, J. Mater. Process. Technol. 214 (2014) 253-266

14. L. Guo, H. Yang, Towards a steady forming condition for radial-axial ring rolling, Int. J. Mech. Sci. 53 (2011) 286-299

15. X. Han, L. Hua, G. Zhou et al., FE simulation and experimental research on cylindrical ring rolling, J. Mater. Process. Technol. 214 (2014) 1245-1258
16. C. Wang, H.J.M. Geijselaers, E. Omerspahic et al., Influence of ring growth rate on damage development in hot ring rolling, J. Mater. Process. Technol. 227 (2016) 268-280

17. M. Wang, H. Yang, Z.C. Sun et al., Analysis of coupled mechanical and thermal behaviors in hot rolling of large rings of titanium alloy using 3D dynamic explicit FEM, J. Mater. Process. Technol. 209 (2009) 3384-3395

18. N. Anjami, A. Basti, Investigation of rolls size effects on hot ring rolling process by coupled thermo-mechanical 3D-FEA, J. Mater. Process. Technol. 210 (2010) 1364-1377

19. M. Wang, H. Yang, L. Guo et al., Effects and optimization of roll sizes in hot rolling of large rings of titanium alloy, Rare Metal Mater. Eng. 38 (2009) 393-397

20. L. Guo, F. Wang, L. Liang et al., New idea and advances in intelligent simulation and optimization of high-performance ring rolling process, J. Netshape Form. Eng. 9 (2017) 1-11 [in Chinese]

21. D. Yang, Research on intelligent modeling and simulation of radial-axial rolling process for large 2219 aluminum alloy ring based on force feedback control, Northwestern Polytechnical University, 2017 [in Chinese]

22. L. Liang, L.G. Guo, X.C. Li et al., Intelligent simulation for real-timely force-controlled radial-axial rolling process of supersized aluminium alloy rings, Proc. Manuf. 15 (2018) 105-112

23. B. Huang, C. Li, L. Shi et al., China materials engineering canon $[\mathrm{M}]$. Chemical Industry Press, Beijing, China, 2005, pp. 566-577 [in Chinese]

24. C. Shen, Research on material constitution models of TA15 and TC11 titanium alloys in hot deformation processes, Northwestern Polytechnical University, 2007 [in Chinese]

25. S. Zhu, Deformation and microstructure evolution in whole process of radial-axial ring rolling of TA15 titanium alloy [D]. Northwestern Polytechnical University (2015) [in Chinese]

26. X. Song, Study on the forming features and process of large scale TA15 titanium alloy aviation structural parts, Chongqing University, 2011 [in Chinese]

Cite this article as: Xuechao Li, Lianggang Guo, Yifan Wang, Lei Liang, Rolling paths design assisted by target-temperature driven intelligent FE simulation of radial-axial ring rolling, Manufacturing Rev. 6, 20 (2019) 